\title{
Contributions to the taxonomy of the ant genus Echinopla Smith, 1857 (Hymenoptera, Formicidae)
}

\author{
Herbert Zettel $^{1}$, Alice Laciny ${ }^{1}$ \\ $12^{\text {nd }}$ Zoological Department, Natural History Museum, Burgring 7, 1010 Vienna, Austria \\ http://zoobank.org/BF4238DA-C6A2-4AF0-AB80-697A1FFF3374 \\ Corresponding author: Herbert Zettel (herbert.zettel@nhm-wien.ac.at)
}

Received 14 April 2015

Accepted 11 May 2015

Published 4 June 2015

Academic editor:

Michael Ohl

\section{Key Words}

ants

Formicidae

Echinopla

new species

new status

lectotype

new records

south-eastern Asia

Sumatra

Borneo

Philippines

\begin{abstract}
Sixteen species of Echinopla Smith, 1857 distributed west of Weber's Line are treated, including eight species described as new: E. madli sp. n. from southern Thailand and Borneo, E. wardi sp. n. from West Malaysia, E. fisheri sp. n., E. circulus sp. n., E. mezgeri sp. n., and E. subtilis sp. n. from Borneo, E. brevisetosa sp. n. and E. angustata sp. n. from the Philippines. Lectotypes are designated for E. lineata Mayr, 1862 and $E$. senilis Mayr, 1862, stat. rev., and differences between the two species are pointed out. New records are presented for E. melanarctos Smith, 1857 (West Malaysia, Sumatra, Borneo), E. pallipes Smith, 1857 (Borneo), E. tritschleri Forel, 1901 (West Malaysia, Borneo), E. cherapunjiensis Bharti \& Gul, 2012 (Laos, West Malaysia), E. lineata Mayr, 1862 (Singapore, Borneo), E. cf. pseudostriata Donisthorpe, 1943 (Philippines), and E. cf. vermiculata Emery, 1898 (Philippines).
\end{abstract}

\section{Introduction}

Echinopla Smith, 1857 is among the small genera of camponotine ants. The 24 described species (Bolton 2015, plus E. senilis Mayr, 1862, stat.rev.) are distinguished by bizarre body structures and distributed from eastern India to Australia. Half of them (twelve species) live exclusively east of Weber's Line (Moluccas, New Guinea, Australia) and eleven species are restricted to the area west of Weber's Line (south-eastern Asia including north-eastern India and southern China, Nicobar Islands, Greater Sunda Islands, Philippines, and Sulawesi). A single polymorphic species, Echinopla striata Smith, 1857, is recorded from both sides in several subspecies, but it is possibly an assemblage of several similar species. Most species were described in the $19^{\text {th }}$ and the first half of the $20^{\text {th }}$ century by short verbal notes, but one species was described recently (Bharti and $\mathrm{Gul}$ 2012). This poor taxonomic treatment is probably caused by the scarcity of individuals. The species of Echinopla typically inhabit the canopy of tropical forests. For this reason records are scarce and often based on single or few individuals caught by chance. Recently, some material was successfully obtained by tree fogging. In contrast to the relatively low species number, many structural characteristics are very variable among the species of Echinopla and make identification simple compared to the related genera Camponotus and Polyrhachis, each containing many sibling or cryptic species. The recent development of internet websites that grant access to large numbers of pictures of types and non-type specimens (e.g., Antbase 2015, 
Antweb 2015, Discover Life 2015) makes the recognition of the described taxa more reliable than in the past.

This study aims to add knowledge of sixteen species (including eight new species) from west of Weber's Line, chiefly from the Asian mainland, from Borneo, and from the Philippine Islands. The taxonomy of Echinopla striata sensu lato is preliminarily excluded, because the treatment of this species (or species complex) should be based on larger samples to evaluate its geographic variation. In addition, taxonomic problems in two closely related species, E. pseudostriata Donisthorpe, 1943 (Philippines) and E. vermiculata Emery, 1898, are addressed.

\section{Methods}

Specimens were dry mounted on card squares or triangles. Examination of specimens was carried out with binocular microscopes; measurements were taken at magnifications up to $240 \times$. Stacked digital images were taken with a Leica DFC camera attached to a Leica MZ16 binocular microscope with the help of Leica Application Suite V3, stacked with ZereneStacker 64-bit, and processed with Adobe Photoshop 7.0.

\section{Acronyms of collections}

CAS California Academy of Sciences, San Francisco, U.S.A.

MCB D. Mezger Collection, Balingen, Germany

NHMW Natural History Museum Vienna, Austria

NMM National Museum of the Philippines, Manila, the Philippines

UKL University of Koblenz-Landau (Campus Landau), Germany

WCD P.S. Ward Collection, Davis, California, U.S.A.

SCV D.M. Sorger Collection, Vienna, Austria

ZCV H. Zettel Collection, Vienna, Austria

\section{Measurements (in millimetres) and indices}

TL Total length. Length of entire specimen measured in dorsal view with head stretched out, from anterior margin of mandible to apex of abdomen, or the added lengths of head (including mandibles), alitrunk, petiole, and gaster in specimens mounted otherwise.

$\mathrm{HW}_{1} \quad$ Head width. Maximum width of head in full-face view including eyes.

$\mathrm{HW}_{2}$ Head width without eyes. Maximum width of head in full-face view excluding eyes.

HL Head length. Maximum length of head in fullface view, excluding mandibles, measured from anterior-most point of clypeus to posterior-most point of head vertex, parallel to midline, including cuticular protrusions if present.

EL Eye length. Maximum diameter of compound eye, measured in lateral view.
SL Scape length. Maximum length of antennal scape in dorsal view excluding basal neck and condyle.

SW Scape width. Maximum width of antennal scape, measured dorsally, usually within distal third of scape.

HaL Hair length. Length of the longest standing hair on scape, measured from apex to base.

PML Promesonotal length. Length of promesonotum, measured along midline dorsally from anterior-most point (excluding collar) to mesometanotal suture.

PMW Promesonotal width. Maximum width of promesonotum measured dorsally, including spines or tubercles if present.

PpL Propodeal length. Length of propodeum, measured dorsomedially from mesometanotal suture to posterior-most point.

PpW Propodeal width. Maximum width of propodeum measured dorsally.

PH Petiole height. Maximum height of the petiole in lateral view, measured from ventral-most point of petiolar sternum to dorsal apex, including spines or tubercles if present.

PL Petiole length. Maximum length of petiole in lateral view, measured from inflexion point of anterior constriction to posterior margin, perpendicular to axis of maximum height.

PW Petiole width. Maximum width of petiole in dorsal view, including spines or tubercles if present.

GL Gastral length. Maximum length of first gastral tergite measured dorsally from anterior-most point of first gastral segment to its posterior-most point (further tergites not included if protruding).

GW Gastral width. Maximum width of first gastral tergite measured dorsally, perpendicular to midline.

CI Cephalic index. $\mathrm{HW}_{1} / \mathrm{HL} \times 100$.

SI Scape index. SL $/ \mathrm{HW}_{1} \times 100$.

MI Mesosoma index. $(\mathrm{PML}+\mathrm{PpL}) / \mathrm{PMW} \times 100$.

\section{Treatment of species}

The species are ordered by similarity according to the following scheme:

Five new species that have a polyporous surface, i.e. multiple closely set pores in the integument (see Fig. 1).

Four described and one new species having "pedestals" on the mesonotum, i.e. socket-shaped protuberances of the integument bearing a long apical seta, surrounded by a subapical ring of short, horizontally projecting hairs (see Figs 22 and 23; also see Gnatzy and Maschwitz 2006 for detailed description).

Two new species with finely punctured gaster tergite 1 , i.e. the dorsal gastral integument is matt with subtle sculpture, without pores, protuberances or rugae (see Figs 29 and 33).

Notes on four described species with predominantly striate surface structure, i.e. the integument bears a sculpture of longitudinal, often parallel lines (see Fig. 41). 


\section{Echinopla madli sp. n.}

http://zoobank.org/938C50EB-DDD4-48C5-B744-1138ED2353ED

Figs $1-4$

Type material. Holotype (worker, NHMW) from Thailand, Satun Province, Thale Ban National Park, 10-16. III.1993, leg. Michael Madl. Paratype (worker, CAS) from Borneo, Sabah, Danum Valley, Field Centre, 525 $\mathrm{m}$ a.s.1., $4.963056^{\circ} \mathrm{N} ; 117.802806^{\circ} \mathrm{E}, 16-26 . V I I I .2010$, rainforest, Ant Course 2010, unknown collector.

Non-type material. 3 workers (UKL, NHMW) from Borneo, Sabah, Poring Spring, lower montane mixed dipterocarp forest, > $650 \mathrm{~m}$, Aporusa sp., fogging, 9-21. II.1993, leg. A. Floren (A50/F4, A51/F5).

Diagnosis (worker). Predominantly black, very small, stout species, TL $=3.9-4.6 \mathrm{~mm}$. Surface polyporous, dorsal margins of mesosoma with sharp tubercles. Head wider than long $(\mathrm{CI}=104-115)$. Mesosoma roughly one fourth longer than pronotal width (MI 120-131), with sharp and deep mesometanotal suture. Pronotum hardly wider than head, if eyes excluded. Propodeum shorter than promesonotum. Petiole dentate, with 1-2 sharp teeth and 0-2 smaller denticles laterally below lateral spine. Gaster tergite 1 with relatively small pores and wide, strongly shiny interspaces; on disk subcumbent pilosity very sparse. Standing setae on dorsal surface of trunk, on legs and scape relatively short. Setae on tibia abundant, surpassing base of distally following setae.

Description. Measurements of holotype worker: TL 4.3; HW 1.17; HW 1.10; HL 1.07; EL 0.23; SL 0.91; SW 0.12; HaL 0.15; PML 0.76; PMW 1.11; PpL 0.59; PpW 1.04; PH 0.45; PL 0.38; PW 1.03; GL 1.24; GW 1.22. Indices: CI 110; SI 78; MI 122.

Measurements of paratype worker: TL 3.9; $\mathrm{HW}_{1} 1.15$; $\mathrm{HW}_{2}$ 1.07; HL 1.00; EL 0.22; SL 0.89; SW 0.12; HaL 0.18; PML 0.72; PMW 1.09; PpL 0.59; PpW 0.98; PH 0.45; PL 0.38; PW 0.96; GL 1.17; GW 1.15. Indices: CI 115; SI 77; MI 120.

Measurements of non-type workers: TL 4.4-4.6; HW 1.11-1.20; $\mathrm{HW}_{2}$ 1.00-1.11; HL 1.07-1.11; EL 0.220.25 ; SL 0.93-0.96; SW 0.13-0.14; HaL 0.11-0.13; PML 0.74-0.78; PMW 1.04-1.12; PpL 0.61-0.67; PpW 0.96-1.04; PH 0.46 (two measured); PL 0.36-0.38; PW 0.97-1.04; GL 1.26-1.37; GW 1.20-1.30. Indices: CI 104-108; SI 80-85; MI 129-131.

Structures: Head wider than long, subtrapezoidal, with slightly convex sides; dorsally and laterally polyporous, with closely set pores, posterolaterally with a few very small tubercles, matt; ventral surface smooth and shiny. Compound eye relatively small, moderately protruding, positioned slightly behind mid-length of head. Frons of type specimens with prominent median carina; frontal lobes chiefly horizontally oriented, completely covering antennal fossae in dorsal aspect, maximum distance of margins at mid-length, slightly greater than half of $\mathrm{HW}_{2}$. Clypeus of type specimens with prominent median carina, anterior margin weakly convex. Mandibles striate, masti- catory margin with five teeth. Antennal scape moderately long, weakly s-curved, steadily widened from base to apex; antennomeres 8-10 slightly wider than long.

Mesosoma stout, length only 1.2 times pronotum width in type specimens; propodeum shorter than promesonotum. Surface polyporous, with closely set pores, dorsal margins with sharp tubercles. Pronotum with strongly developed angles, about as wide as head excluding eyes. Promesonotal suture weak, indicated by a convex row of deeper pits. Mesometanotal suture sharp, narrow and deep. In dorsal aspect mesosoma with waist-like incision in front of propodeum. Legs moderately long; femora not much widened.

Petiole wide and stout, subtriangular in lateral, strongly transverse in dorsal aspect; surface structure as on mesosoma; sharp dorsal crest bearing four sharp teeth medially and another two pairs of small denticles laterally; lateral tooth strongly developed; below lateral tooth with two sharp teeth and 0-2 (asymmetrical) small denticles. Gaster tergite 1 as wide as long, strongly convex, and completely covering the following tergites; hind margin moderately convex, finely serrate; surface polyporous, interspaces smooth and shiny; distances of pores mostly slightly larger than their diameters.

Pilosity: Head (except ventral surface), mesosoma, and petiole with dense, appressed white pilosity and moderately long white standing setae. Gaster tergite 1 with very sparse appressed pilosity on disc, but relatively dense at sides; standing setae anteriorly much longer than posteriorly. White standing setae on scape about as long as the setae on head. Legs with fine appressed pilosity. Femora with some long standing setae on flexor side. Pilosity on tibiae and first tarsomeres oblique, relatively long and dense.

Colour: Trunk black, without metallic shimmer, appearing grey by whitish pilosity. Antenna with black scape and base of funiculus, distal part testaceous. Mandible basally black, distally testaceous; other mouthparts yellowish. Legs of type specimens testaceous, but forecoxa black, apices of femora, tibiae and first tarsomeres infuscated. Legs of non-type specimens predominantly blackish.

Comparative notes. Echinopla madli sp. n. and the following four new species belong to a peculiar species group that is characterized by small body size (except $E$. fisheri sp. n.), black colour (lack of metallic lustre), and polyporous surface structures that resemble the pores of coral rocks (see Stitz 1938). Other species groups can be defined by different surface structures, at least on head and mesonotum, either fine puncturation, or striations consisting of sharp rugae, or high, truncate tubercles ("pedestals") that give the specimens a spiny appearance. A peculiar character of E. madli sp. n. is gaster tergite 1 that is hardly longer than wide and has a shiny, weakly pilose and sparsely pitted disc. These characters distinguish it immediately from closely related species in the region (E. wardi sp. n., E. brevisetosa sp. n., and E. angustata sp. n.). A similarly structured tergite 1 is 

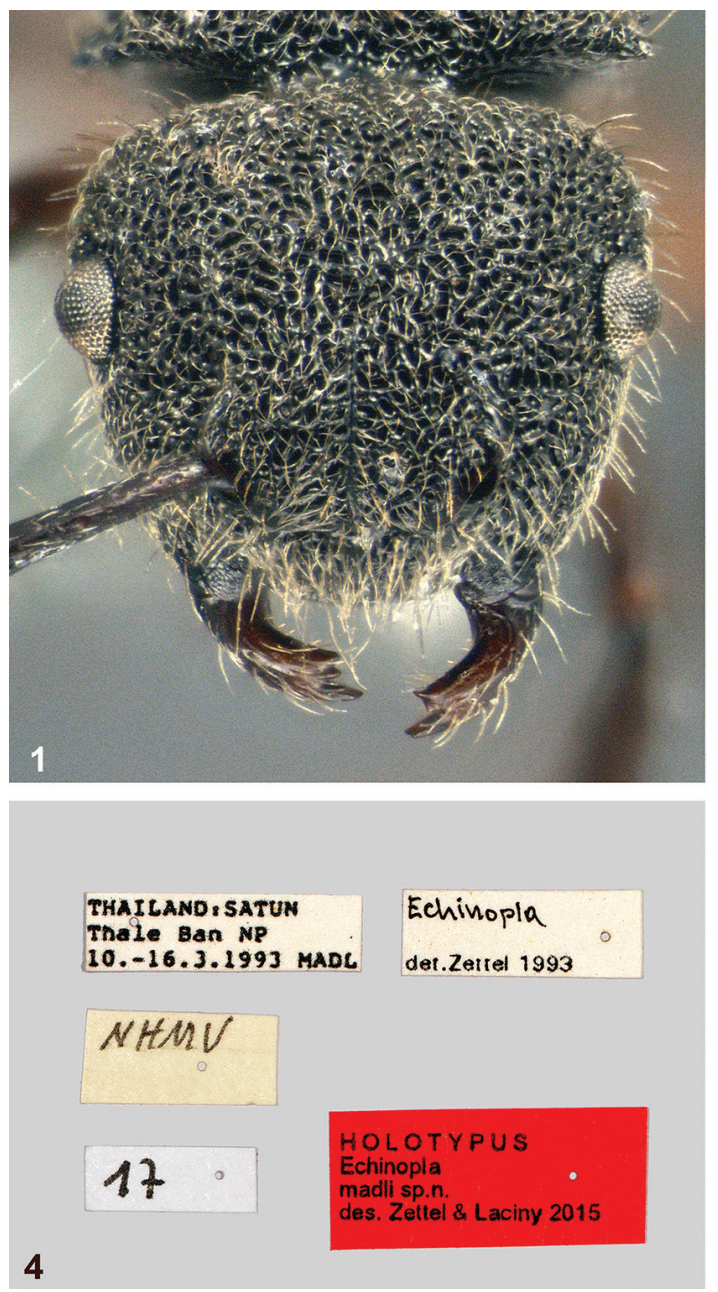
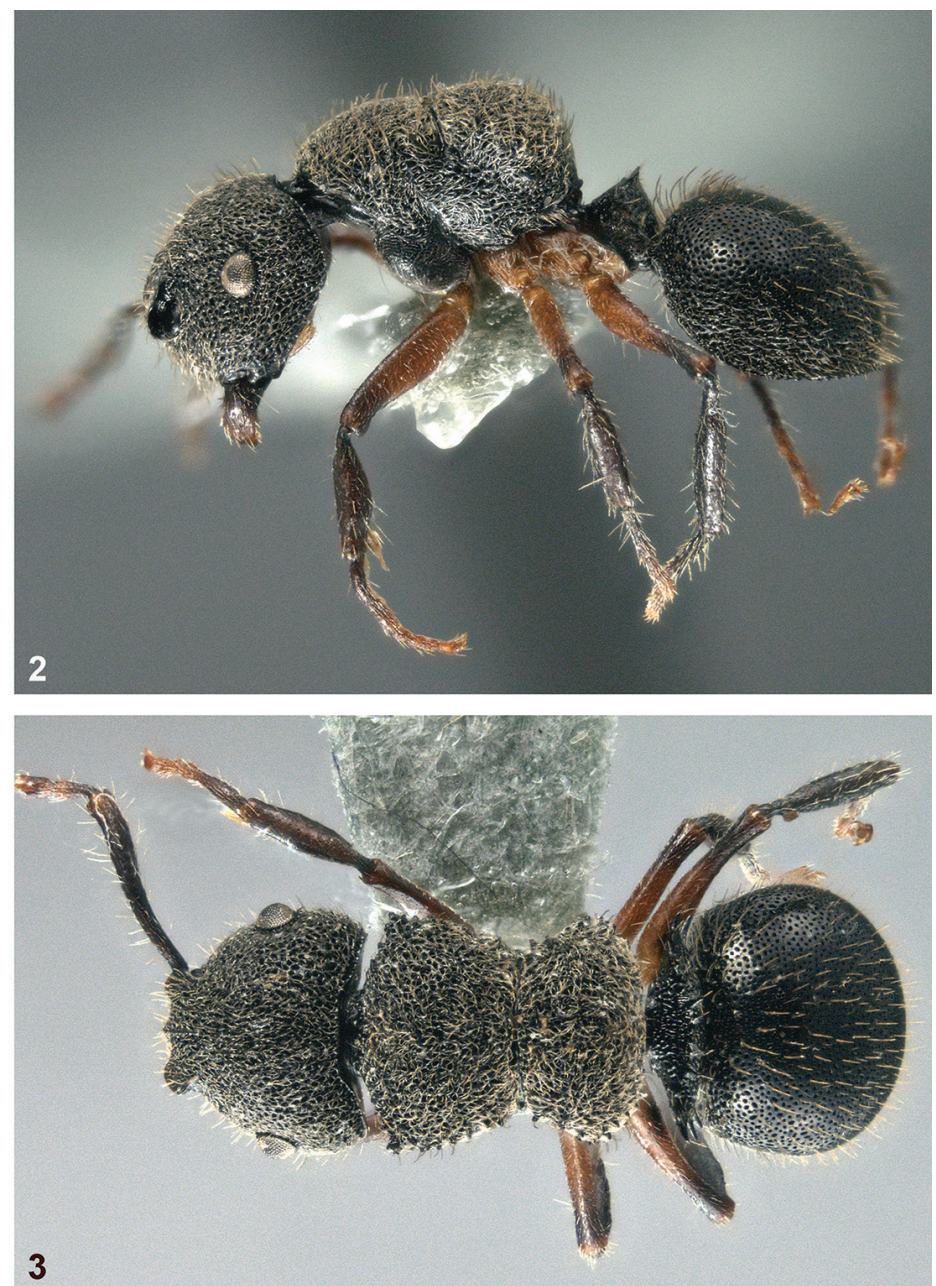

(4) Labels. found in E. dubitata Smith, 1862 from Sulawesi, but this is a slender species with black tarsi, weakly developed appressed pilosity and long black standing setae. Images of E. dubitata are presented by Antweb (2015).

We studied five workers of $E$. madli sp. n. from three localities and noted a high variability. Whereas the paratype from Danum Valley (Sabah) largely agrees with the holotype from southern Thailand, further Sabah specimens from Poring Spring differ by largely black legs (except one callow worker), reduced median carinae on frons and clypeus, and some morphometric data (e.g., higher SI, lower CI). The examination of more material would be necessary to clarify the status of this population.

Etymology. Dedicated to our colleague Michael Madl, Frauenkirchen, Austria, who collected the holotype specimen.

\section{Echinopla wardi sp. n.}

http://zoobank.org/044DDB4D-67C1-4A69-8FF8-677588D569F9 Figs 5-8

Type material. Holotype (worker, NHMW) from Malaysia, Johor, $13 \mathrm{~km} \mathrm{NE} \mathrm{Kota} \mathrm{Tinggi,} 1^{\circ} 49^{\prime} \mathrm{N}$; $103^{\circ} 50^{\prime} \mathrm{E}$,
$50 \mathrm{~m}$ a.s.1., 22.XI.1988, on low vegetation in secondgrowth rain forest, leg. Philip S. Ward (PSW09591-12; ANTWEB CASENT 0280337). Paratype (worker, ZCW) from West Malaysia, Pahang, 70 km SW Kuala Rompin, Endau Rompin National Park, Gunung Beremban, 600 m a.s.1., 13.IV.-3.V.2010, leg. Petr Čechovský.

Diagnosis (worker). Predominantly black, small species, TL $=3.8-4.3$. Surface polyporous, dorsal margins of mesosoma with sharp tubercles. Head wider than long (CI $=110)$. Mesosoma roughly 1.25 times as long as pronotal width (MI 122-126), with sharp and deep incision in front of propodeum. Pronotal width equal to head width, if eyes excluded. Propodeum shorter than promesonotum. Petiole dentate, with three sharp teeth laterally below lateral spine. Gaster tergite 1 about one fourth longer than wide, anteriorly with relatively large pores and shiny interspaces; disk with dense subcumbent pilosity. Setae on dorsal surface, legs and scape relatively short. Setae on tibia reaching or surpassing base of distally following setae.

Description. Measurements of holotype worker: TL 3.8; $\mathrm{HW}_{1}$ 1.11; $\mathrm{HW}_{2}$ 1.02; HL 1.01; EL 0.23; SL 0.96; SW 0.12; HaL 0.16; PML 0.72; PMW 1.02; PpL 0.57; PpW 0.91; PH 0.45; PL 0.40; PW 0.91; GL 1.27; GW 1.11. Indices: CI 110; SI 80; MI 126. 

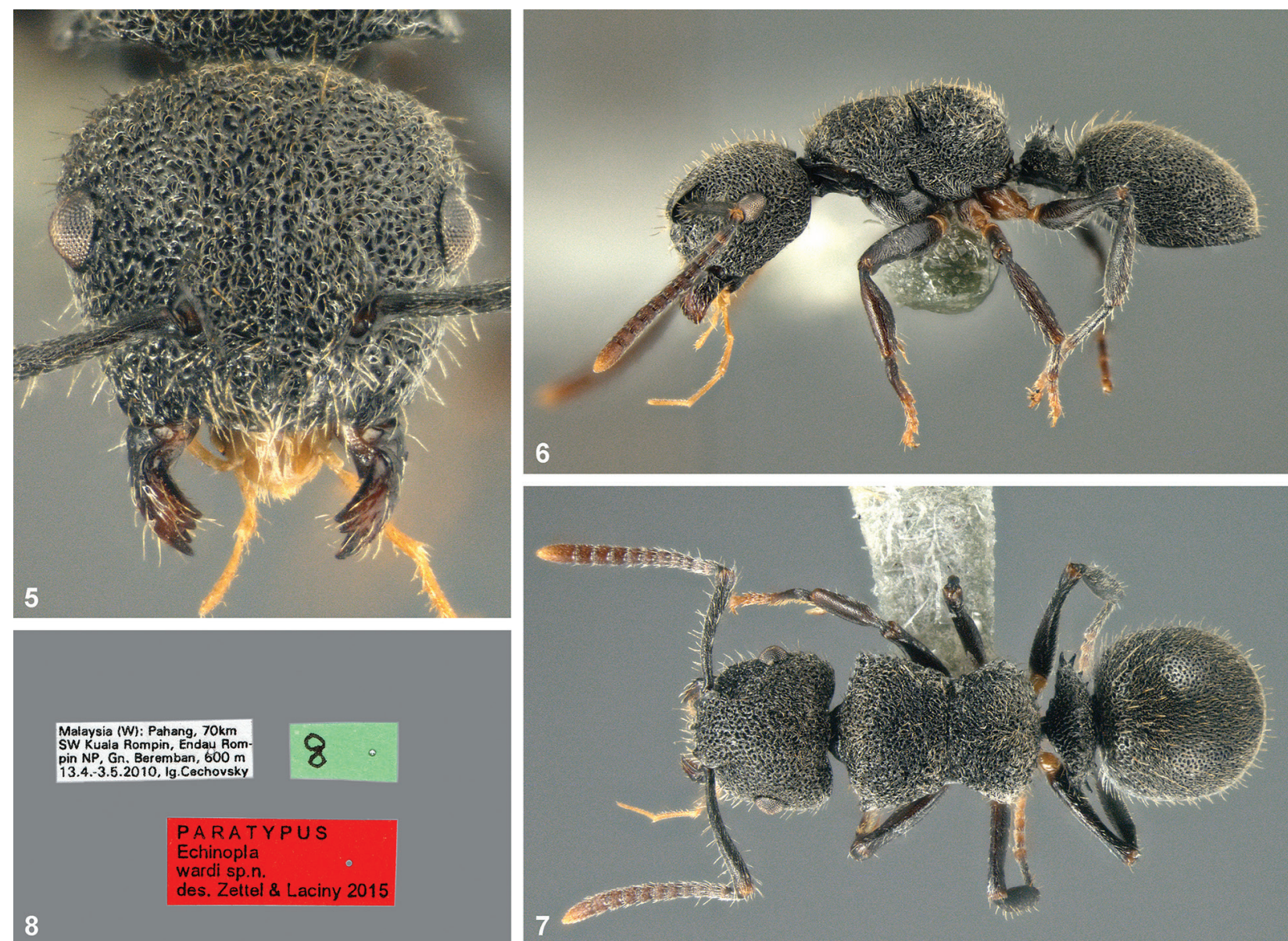

Figures 5-8. Echinopla wardi sp. n., paratype: (5) Head, full face view. (6) Habitus, lateral view. (7) Habitus, dorsal view. (8) Labels.

Measurements of paratype worker: TL 4.3; $\mathrm{HW}_{1} 1.17$; HW 1.11; HL 1.07; EL 0.23; SL 0.96; SW 0.12; HaL 0.14; PML 0.76; PMW 1.11; PpL 0.59; PpW 1.00; PH 0.51; PL 0.38; PW 1.03; GL 1.37; GW 1.24. Indices: CI 110; SI 81; MI 122.

Structures: Head wider than long, subtrapezoidal, with slightly convex sides; dorsally and laterally polyporous, with closely set pores, posterolaterally with a few minute tubercles, matt; ventral surface smooth and shiny. Compound eye relatively small, moderately protruding, positioned slightly behind mid-length of head. Frons with prominent median carina; frontal lobes chiefly horizontally oriented, largely covering antennal fossae in dorsal aspect, maximum distance of margins slightly behind mid-length, as great as half of $\mathrm{HW}_{2}$. Clypeus with distinct median carina, anterior margin almost straight. Mandibles striate, masticatory margin with five teeth. Antennal scape moderately long, weakly s-curved, steadily widened from base to apex; antennomeres 8-10 approximately as wide as long.

Mesosoma stout, length ca. 1.25 times pronotum width; propodeum shorter than promesonotum. Surface polyporous, with closely set pores, dorsal margins with sharp tubercles. Pronotum with distinct lateral angles, as wide as head excluding eyes. Promesonotal suture weak, indicated by a convex row of deeper pits. Mesometanotal suture sharp and deep, medially narrow, laterally widened. In dorsal aspect mesosoma with waist-like incision in front of propodeum. Legs moderately long; femora not much widened.

Petiole wide and stout, subtriangular in lateral view, strongly transverse in dorsal aspect; surface structure as on mesosoma; sharp dorsal crest bearing four sharp teeth medially and one pair of small denticles laterally; lateral tooth strongly developed; below lateral tooth with one long and two short, sharp teeth. Gaster tergite 1 clearly longer than wide, completely covering the following tergites; hind margin moderately convex, finely serrate; surface polyporous, interspaces smooth and shiny; distances of pores mostly smaller than their diameters.

Pilosity: Entire trunk dorsally and laterally with dense, appressed white pilosity and moderately long white standing setae; only the standing setae on anterior part of gaster tergite 1 distinctly longer. White standing setae on scape about as long as the setae on head. Legs with fine appressed pilosity. Femora with some long standing setae on flexor side. Tibiae and first tarsomeres of middle and hind leg with rows of oblique white setae; their length as long as their distance.

Colour: Trunk black, without metallic shimmer, appearing grey by whitish pilosity. Antenna with black scape; funiculus basally black, becoming gradually paler 
towards testaceous apex. Mandible basally black, distally brown; other mouthparts yellowish. Legs chiefly blackish, but coxae of middle and hind legs brown, all trochanters dark testaceous, and tarsi distally reddish testaceous.

Comparative notes. Echinopla wardi sp. n. is similar to E. australis Forel, 1901 from Australia, but this species has yellow legs and funiculus, relatively long pilosity, and pronotal width distinctly smaller than head width. Images of E. australis are presented by Antweb (2015). According to the original description (André 1892), E. rugosa André, 1892 from Borneo has similar structures of mesosoma and petiole, but differs by uniformly black colour with bronze shimmer and slightly smaller size. Unfortunately the holotype depository of this enigmatic species is unknown and no further specimen has become known. See also notes for E. madli sp. n. and E. brevisetosa sp. n.

Figures 5-8 are taken from the paratype whereas the holotype is illustrated by Antweb (2015) with specimen number CASENT 0280337.

Etymology. Dedicated to Phil S. Ward (University of California) who collected the holotype and kindly donated it to NHMW.

\section{Echinopla brevisetosa sp. n.}

http://zoobank.org/1AE042DE-C090-4D0F-973A-54112FA1C4E8

Figs 9-12

Type material. Holotype (worker, NMM) and paratype (worker, ZCW) from the Philippines, Mindanao Island, Bukidnon Province, Malaybalay City, Kaamulan site, $650 \mathrm{~m}$ a.s.1., 15-20.III.2000, leg. H. Zettel.

Diagnosis (worker). Predominantly black, small, stout species, $\mathrm{TL}=4.0$. Surface polyporous, dorsal margins of mesosoma with sharp tubercles. Head wider than long $(\mathrm{CI}=106-109)$. Mesosoma roughly 1.3 times as long as pronotal width, with sharp and deep incision in front of propodeum. Pronotal width subequal to head width, if eyes excluded. Propodeum slightly shorter than promesonotum. Petiole dentate, with one long tooth and two small denticles laterally below lateral tooth. Gaster tergite 1 anteriorly with relatively fine pores and very narrow interspaces. Setae on dorsal surface, legs and scape relatively short. Short setae on tibia not reaching base of distally following setae.

Description. Measurements of holotype worker: TL 4.0; $\mathrm{HW}_{1}$ 1.09; $\mathrm{HW}_{2}$ 0.99; HL 1.02; EL 0.23; SL 0.87; SW 0.11; HaL 0.08; PML 0.67; PMW 0.97; PpL 0.61; PpW 0.88; PH 0.50; PL 0.37; PW 0.98; GL 1.20; GW 1.17. Indices: CI 106; SI 80; MI 133.

Measurements of paratype worker: TL 3.9; HW 1.11 ; $\mathrm{HW}_{2}$ 0.98; HL 1.02; EL 0.22; SL 0.91; SW 0.12; HaL 0.09; PML 0.65; PMW 1.02; PpL 0.63; PpW 0.91; PH 0.46; PL 0.36; PW 0.98; GL 1.22; GW 1.20. Indices: CI 109; SI 82; MI 126.

Structures: Head wider than long, subtrapezoidal, with slightly convex sides; dorsally and laterally polyporous, with closely set pores, posterolaterally with a few minute tubercles, matt; ventral surface smooth and shiny. Compound eye relatively small, moderately protruding, positioned almost at mid-length of head (very slightly behind). Frons with prominent median carina; frontal lobes chiefly horizontally oriented, in dorsal aspect covering antennal fossae only in part, maximum distance of margins clearly behind mid-length, slightly greater than half of $\mathrm{HW}_{2}$. Clypeus with distinct median carina, anterior margin almost straight. Mandibles striate, masticatory margin with five teeth. Antennal scape moderately long, almost straight, steadily widened from base to apex; antennomeres 8-10 approximately as wide as long.

Mesosoma stout, length roughly 1.3 times pronotum width; propodeum slightly shorter than promesonotum. Surface polyporous, with closely set pores, dorsal margins with sharp tubercles. Pronotum with distinct lateral angles, approximately as wide as head excluding eyes. Promesonotal suture very weak, indicated by a few deeper pits. Mesometanotal suture sharp, narrow and deep. In dorsal aspect mesosoma with waist-like incision in front of propodeum. Legs moderately long; femora not much widened.

Petiole wide and stout, subtriangular in lateral, strongly transverse in dorsal aspect; surface structure as on mesosoma; sharp dorsal crest bearing six sharp teeth of slightly varying length; lateral tooth strongly developed; below lateral tooth with one long tooth and two small denticles. Gaster tergite 1 slightly longer than wide, completely covering the following tergites; hind margin convex, finely serrate; surface polyporous, interspaces smooth and shiny; distances of pores everywhere clearly smaller than their diameters.

Pilosity: Entire trunk dorsally and laterally with dense, appressed white pilosity and moderately long white standing setae; standing setae on anterior part of gaster tergite 1 slightly longer. White standing setae on scape about as long as the setae on head. Legs with fine appressed pilosity. Femora with only $0-3$ standing setae on flexor side. Tibiae and first tarsomeres of middle and hind leg with relatively few oblique white setae; on tibiae their length smaller than their distance.

Colour: Trunk black, without metallic shimmer, appearing grey by whitish pilosity. Antenna with black scape; funiculus reddish dark brown, paler towards apex. Mandible basally black, distally pale brown; other mouthparts yellowish. Legs: forecoxa black; middle and hind coxa and all trochanters pale testaceous; femora and hind tibia blackish brown; other tibiae and tarsi brown, paler towards apical tarsomeres.

Comparative notes. Echinopla brevisetosa sp. n. is similar to $E$. wardi sp. n. from West Malaysia, but has a more slender mesosoma, a relatively longer propodeum and a differently structured petiole that bears one slender tooth and two small denticles below the lateral spine whereas the petiole of $E$. wardi sp. n. has three relatively strong teeth. Echinopla brevisetosa sp. n. differs distinctly from $E$. wardi sp. n. and E. madli sp. n. by the very short tibial setae. 

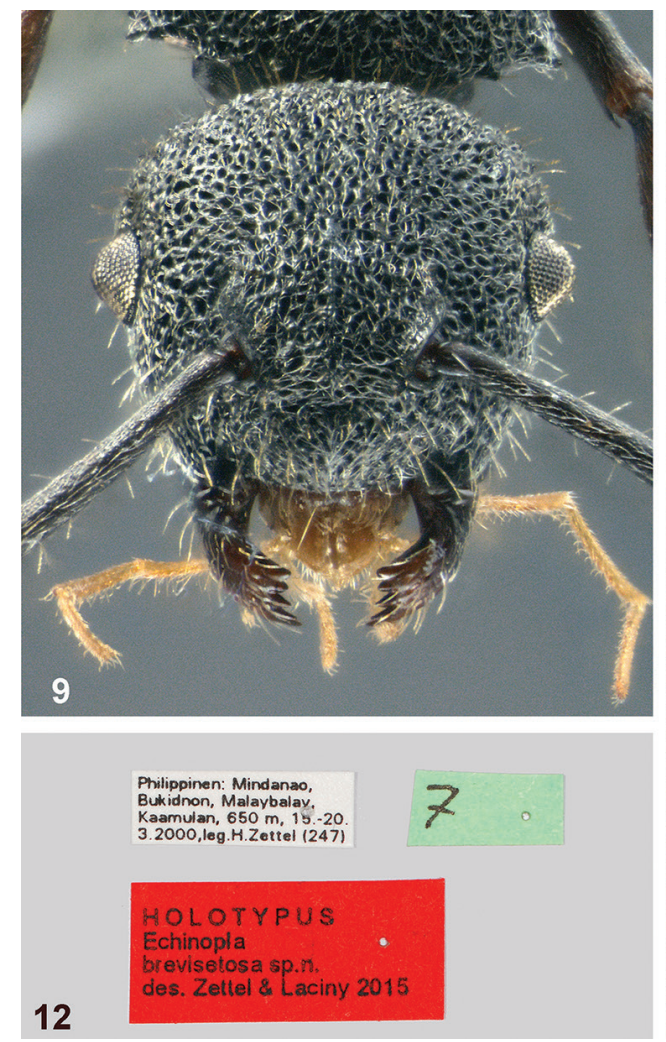
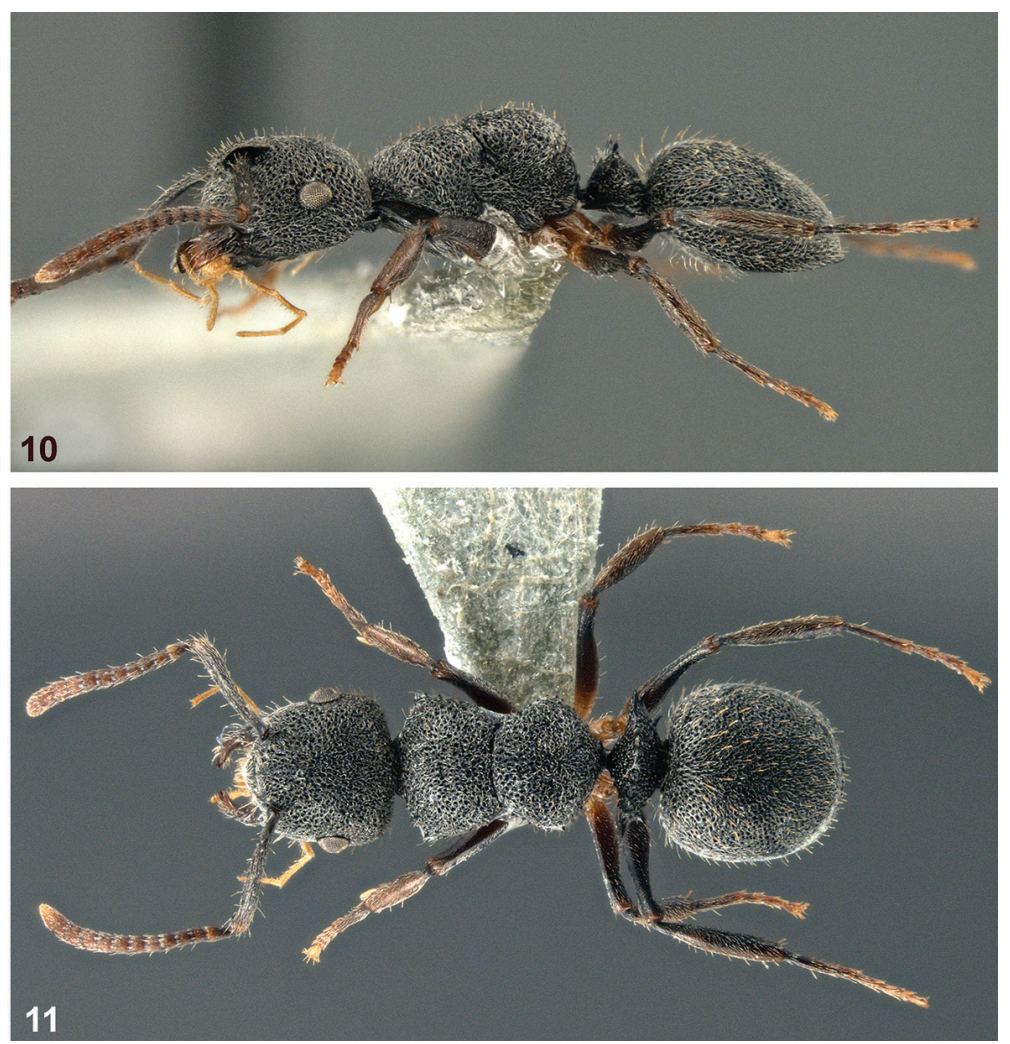

Figures 9-12. Echinopla brevisetosa sp. n., holotype: (9) Head, full face view. (10) Habitus, lateral view. (11) Habitus, dorsal view. (12) Labels.

Etymology. From Latin adjectives brevis meaning short and setosus meaning bristly, and referring to the short pilosity of trunk, scape and legs.

\section{Echinopla angustata sp. n.}

http://zoobank.org/0F71F455-B740-46A3-BD07-1BA2B0A63E4F

Figs $13-16$

Type material. Holotype (worker, NMM) from the Philippines, Negros Island, Negros Oriental Province, Valencia, Apolong, Casaroro Falls, slopes of Cuernos de Negros, 9-13.III.2005, leg. H. Zettel (420), in the National Museum of the Philippines, Manila; two paratypes (workers, ZCW) from the same locality, 3-4.III.2008, leg. H. Zettel (513).

Diagnosis (worker). Predominantly black, small, slender species, $\mathrm{TL}=4.6-4.8$. Surface polyporous, pronotum with one pair of sharp tubercles, otherwise tubercles on mesosoma hardly developed. Head longer than wide (CI =93-94). Mesosoma almost twice as long as pronotal width, with sharp, narrow mesometanotal suture. Pronotal width distinctly smaller than head width, if eyes excluded. Propodeum slightly shorter than promesonotum. Petiole with one pair of dorsal spines, without dentition below prominent lateral spines. Gaster tergite 1 anteriorly with relatively large pores and very narrow interspaces. Setae on dorsal surface, legs and scape relatively short. Short setae on tibia not reaching base of distally following setae.
Description. Measurements of holotype worker: TL 4.6; HW 1.10; HW 0.93; HL 1.17; EL 0.23; SL 1.04; SW 0.13; HaL 0.11; PML 0.87; PMW 0.83; PpL 0.72; PpW 0.73; PH 0.50; PL 0.41; PW 0.83; GL 1.41; GW 1.15. Indices: CI 94; SI 95; MI 192.

Measurements of paratype workers: TL 4.8, 4.8; HW 1.13, 1.16; HW 0.98, 1.00; HL 1.22, 1.24; EL 0.25, 0.24; SL 1.11, 1.11; SW 0.14, 0.13; HaL 0.13, 0.10; PML 0.93, 0.93; PMW 0.87, 0.91; PpL 0.76, 0.76; PpW 0.76, 0.80; PH 0.55, 0.56; PL 0.42, 0.44; PW 0.87, 0.91; GL 1.54, 1.50; GW 1.24, 1.25. Indices: CI 93, 94; SI 98, 95; MI $195,186$.

Structures: Head longer than wide, subovate, with convex sides; dorsally and laterally polyporous, with closely set, relatively large pores, posterolaterally with a very few indistinct tubercles, matt; ventral surface smooth and shiny. Compound eye relatively small, strongly protruding, positioned slightly behind mid-length of head. Frons with prominent median carina; frontal lobes chiefly horizontally oriented, in dorsal aspect covering antennal fossae only in part, maximum distance of margins clearly behind mid-length, slightly greater than half of $\mathrm{HW}_{2}$. Clypeus with short, angularly elevated median carina, anterior margin straight. Mandibles striate, masticatory margin with five teeth. Antennal scape moderately long, almost straight, steadily widened from base to apex; antennomeres 8-10 approximately as wide as long.

Mesosoma slender, length roughly 1.9 times pronotum width; propodeum much shorter than promesonotum. 

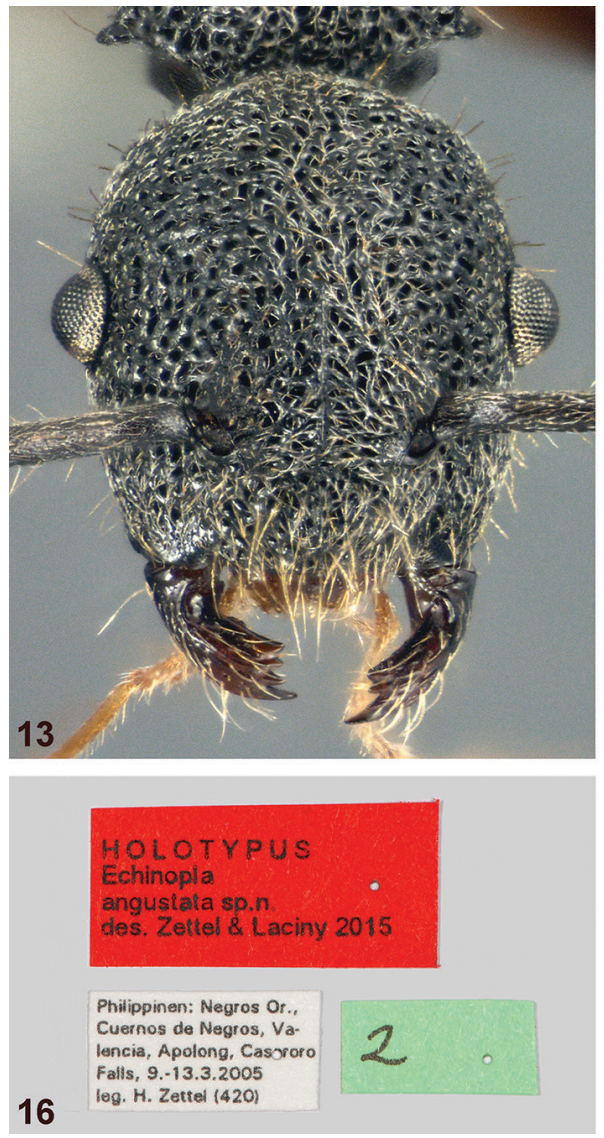
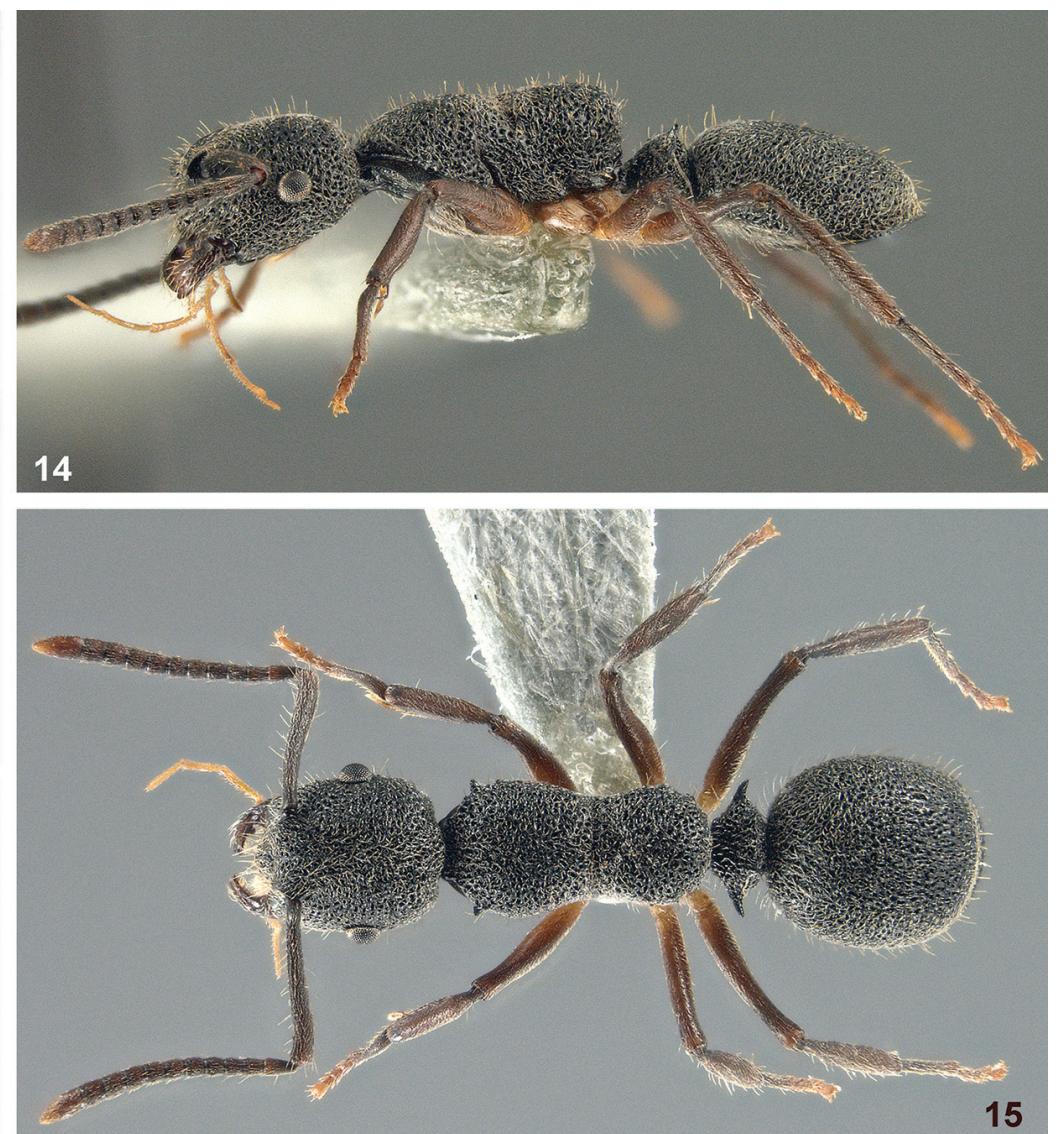

Figures 13-16. Echinopla angustata sp. n., holotype: (13) Head, full face view. (14) Habitus, lateral view. (15) Habitus, dorsal view. (16) Labels.

Surface polyporous, with closely set, relatively large pores, dorsal margins with very few small tubercles. Pronotum rounded, but with distinct lateral teeth, distinctly narrower than head excluding eyes. Promesonotal suture absent. Mesometanotal suture sharp, narrow and deep. "Waist" in front of propodeum weakly developed. Legs moderately long, relatively slender.

Petiole stout, moderately wide, subtriangular in lateral, transverse in dorsal aspect; surface structure as on mesosoma; dorsal apex not sharply crested, bearing one pair of sharp, rather long teeth and occasionally a small medial denticle; below strongly developed lateral teeth without further dentition. Gaster tergite 1 considerably longer than wide, completely covering the following tergites; hind margin convex, serration blunt, in one paratype almost absent; surface polyporous, interspaces smooth and shiny; distances of pores everywhere clearly smaller than their relatively large diameters.

Pilosity: Entire trunk dorsally and laterally with dense, appressed white pilosity and moderately long white and grey standing setae; some standing setae on clypeus and on anterior declivity of gaster tergite 1 longer. White standing setae on scape about as long as the setae on head. Legs with fine appressed pilosity. Femora with only $0-2$ standing setae on flexor side. Tibiae and first tarsomeres of middle and hind leg with oblique white setae; on tibiae their length greater than their distance.
Colour: Trunk black, without metallic shimmer, appearing grey by whitish pilosity. Antenna black or very dark brown, funiculus slightly paler towards apex. Mandible basally black, distally brown; other mouthparts yellowish. Legs chiefly black to dark brown; middle and hind coxa, all trochanters, and bases of femora yellowish to pale testaceous; tarsi towards apical tarsomeres reddish brown.

Comparative notes. Echinopla angustata sp. n. differs from the previous three species by the much more slender body. The tubercles on the mesosomal sides are poorly developed except for one prominent pair on the pronotum. The petiole has no teeth below the lateral spines, and the pits on gaster tergite 1 are relatively coarse.

Etymology. From the Latin adjective angustatus meaning narrow and referring to the slender body.

\section{Echinopla fisheri sp. $\mathbf{n}$.}

http://zoobank.org/E313BDB6-7658-4234-AFAB-E1BFE30CD60B Figs $17-20$

Type material. Holotype (worker, CAS, CASENT 0214564-D01) from Malaysia, Sabah, Danum Valley, Nature Trail, $180 \mathrm{~m}$ a.s.1., $4.96072^{\circ} \mathrm{N} ; 117.80014^{\circ} \mathrm{E}$, in rainforest, 24.VII.2010, leg. B.L. Fisher.

Diagnosis (worker). Predominantly black, mediumsized, slender species, $\mathrm{TL}=6.3$. Surface polyporous, prono- 

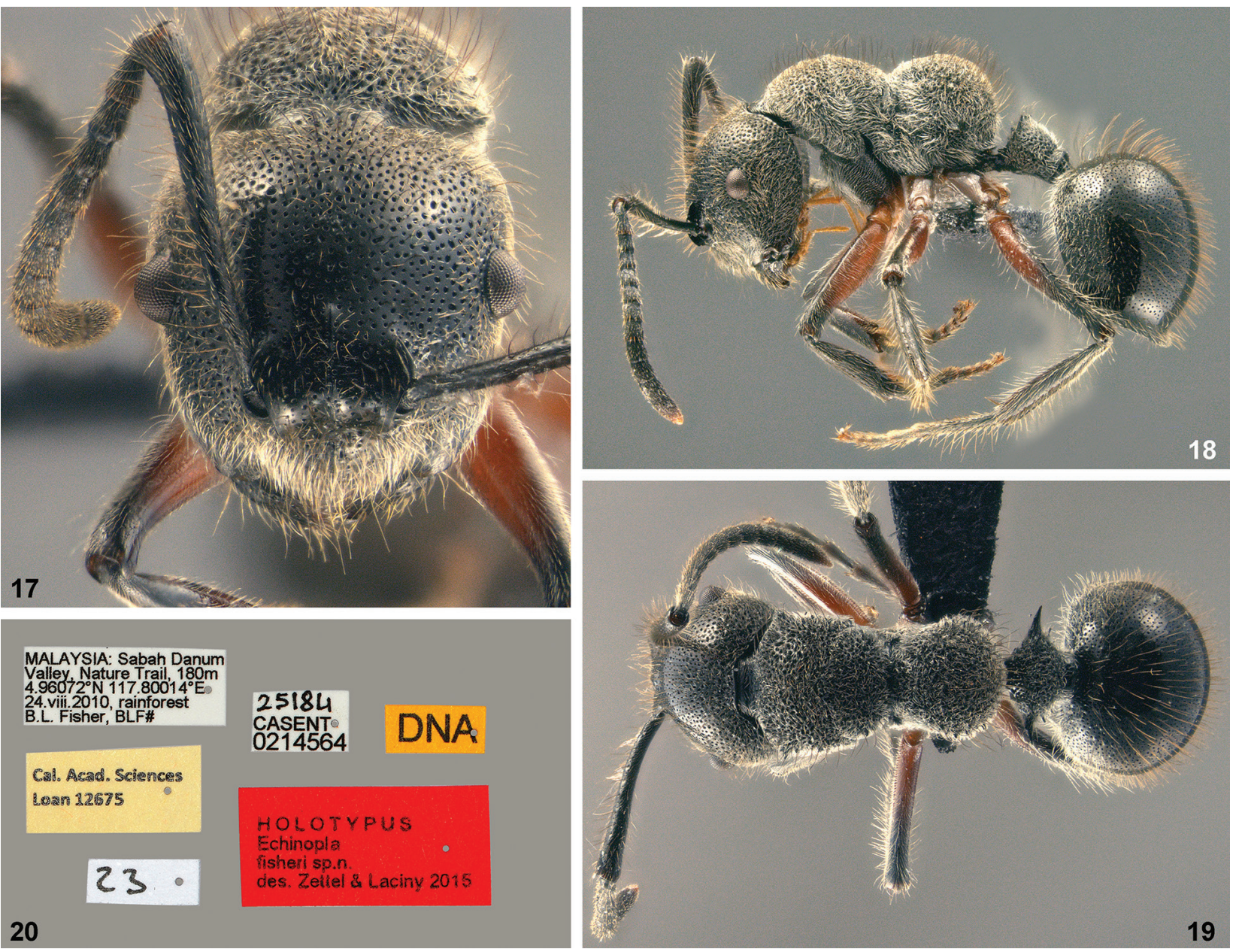

Figures 17-20. Echinopla fisheri sp. n., holotype: (17) Head, full face view. (18) Habitus, lateral view.(19) Habitus, dorsal view. (20) Labels.

tum with one pair of sharp tubercles, otherwise tubercles on mesosoma hardly developed. Head very large, about as wide as long $(\mathrm{CI}=101)$. Mesosoma about two thirds longer than wide $(\mathrm{MI}=166)$, with sharp and very deep mesometanotal suture. Pronotal width much smaller than head width. Propodeum much shorter than promesonotum. Petiole longer than high, with three pairs of dorsal spines and three spines below the prominent lateral spines. Gaster tergite 1 with very fine, sparsely distributed pores, along hind margin with transverse impression. Setae on dorsal surface, legs and scape very long, mostly brown.

Description. Measurements of holotype worker: TL 6.3; $\mathrm{HW}_{1}$ 1.58; $\mathrm{HW}_{2}$ 1.41; HL 1.57; EL 0.27; SL 1.53; SW 0.18; HaL 0.27; PML 1.20; PMW 1.28; PpL 0.93; PpW 1.04; PH 0.54; PL 0.63; PW 1.17; GL 1.87; GW 1.61. Indices: CI 101; SI 97; MI 166.

Structures: Head very large compared to mesosoma, as long as wide, with convex sides and almost straight hind margin bearing a small medial lobe; dorsally and laterally polyporous, unevenly large pores, posteriorly and laterally larger and denser than in centre, shiny; ventral surface smooth and shiny. Compound eye small, slightly protruding, positioned near mid-length of head (slightly posteriorly). Frons with two short sections of a median carina; frontal lobes chiefly horizontally oriented, in fullface view covering antennal fossae only in part, maximum distance of margins near posterior end, smaller than half of $\mathrm{HW}_{2}$. Clypeus with median carina, anterior margin emarginated at middle. Mandibles striate, masticatory margin with five teeth. Antennal scape moderately long, almost straight, steadily widened from base to apex; all antennomeres longer than wide.

Mesosoma slender, length roughly 1.7 times pronotum width; propodeum much shorter than promesonotum. Dorsal outline of both promesonotum and propodeum strongly convex, meeting at the deep incision of a sharp metanotal groove. Promesonotal suture only laterally indicated. Surface polyporous, with closely set, relatively large pores, dorsal margins with few small tubercles, on propodeum more numerous than on promesonotum. Pronotum angular, much narrower than head. "Waist" in front of propodeum well developed in dorsal aspect. Legs comparatively long and slender.

Petiole moderately wide, slender subtriangular in lateral, slightly transverse in dorsal aspect; surface sculpture on node as on the mesosoma, a broad posterior rim smooth; dorsal apex crested with three pairs of sharp, rather long teeth; each side bearing three teeth below a 
strongly developed lateral tooth. Gaster tergite 1 considerably longer than wide, completely covering the following tergites; hind margin convex, with indistinct serration and with shallow emargination at middle; along posterior margin a shallow but rather wide impression; surface polyporous, but pores extremely fine and sparse; interspaces smooth and shiny; distances of pores everywhere several times larger than their diameters.

Pilosity: Trunk dorsally and laterally with dense, appressed white pilosity, lacking only on centre of face and gaster tergite 1. Dorsal surface with very long brown standing setae. Standing setae on scape, femora, tibiae, and first tarsomeres also very long, brown or grey.

Colour: Trunk black, without metallic shimmer, mesosoma appearing grey by whitish pilosity. Antenna black. Mandible black, teeth dark reddish brown; other mouthparts pale yellowish. Legs chiefly black; middle and hind coxa, all trochanters, and femora except their apices reddish.

Comparative notes. Echinopla fisheri sp. n. differs strongly from other species with polyporous surface structure by a very long, dark pilosity of the trunk, a deep metanotal suture that separates the strongly convex promesonotum and propodeum (Fig. 18), and very fine and sparsely distributed pores on gaster tergite 1 (Fig. 19). It is conspicuously larger than the preceding species and it has a distinctly emarginated clypeus margin (straight to convex in the other species) and a petiole that is longer than high (higher than long in the other species).

Notes. Antweb (2015) states that the holotype specimen was sent for barcoding (Guelph CCDB-016889).

Etymology. Dedicated to Brian L. Fisher (California Academy of Sciences) who discovered this extraordinary species.

\section{Echinopla melanarctos Smith, 1857}

Material examined. 1 worker (NHMW) from Indonesia, Sumatra, Aceh Province, Gunung Leuser National Park, Ketambe, 22.II.1990, leg. H. Schillhammer; 1 worker (NHMW) from West Malaysia, Kedah, Gunung Jerai, north of Sungai Petani, 700 m a.s.l., leg. M.A. Jäch; 15 workers, 2 dealate gynes (ZCW, NHMW) from West Malaysia, Kelantan, 30 km NW Gua Musang, Ulu Lalat, Kampong Sungai Om, 800-1000 m a.s.1., 21.VI.-14. VII.2010, leg. Petr Čechovský; 1 gyne (MCB) from Sabah, Danum Valley, Western Trail, $04^{\circ} 58^{\prime} \mathrm{N}$; $117^{\circ} 48^{\prime} \mathrm{E}$, 4.VI.2004, leg. D. Mezger (C 00619); 1 worker (UKL) from Borneo, Sabah, Deramakot Forest Reserve, Plot H196, ca. $5^{\circ} 27^{\prime} \mathrm{N}$; $117^{\circ} 25^{\prime} \mathrm{E}$, ca. 85 m, disturbed loggedover forest, 1998, leg. M. Gossner; 1 gyne (UKL) from Borneo, Sarawak, Gunung Mulu National Park, 0408'N; 1145'ㄹ, leg. D. Mezger (KE91).

Notes. Echinopla melanarctos is the type species of Echinopla. It can be easily recognized by its relatively large size (in workers TL ca. 6.5-8.2 mm, $\mathrm{HW}_{1}$ ca. 2.05-2.44 mm), very spiny appearance, long black hair, and entirely black colour (except palpi). The "spines" are slender, socket-shaped protuberances ("pedestals") of the integument, their apex is truncate and bears a long seta, surrounded by a subapical ring of short, horizontally projecting hairs (bearing resemblance to the pappus of a dandelion seed). They are typical for a group of species also containing E. pallipes, E. circulus sp. n., E. tritschleri, and E. cherapunjiensis. In E. tritschleri, however, the ring of short setae is not horizontally projecting but oblique, therefore the pilosity is less obvious.

Due to the scarcity of specimens, hitherto little is known about the differences between workers and gynes in Echinopla. We were able to study both castes of $E$. melanarctos and noted the following differences: body of gynes larger (TL 8.8-9.7 vs. 6.5-8.2; HW $2.41-2.70$ vs. 2.05-2.44); eyes slightly larger; ocelli present; pedestals lower than in worker, on scutum and scutellum reduced to low tubercles; these parts with coarse, irregular rugae, scutum anteriorly with distinct, long median carina; short pilosity of dorsum less obvious; thoracic structures as typical for winged ant gynes (all examined specimens with wings broken off); scutellum laterally with a short lobe (not with a sharp projection as in some congeners).

Echinopla melanarctos was described from Singapore (Smith 1857) and recorded from Sumatra (Mayr 1872, Emery 1900) and Sipora Island of the Mentawai group (Emery 1900) in Indonesia. A worker from "Banka" deposited in the Zoological State Collection, Munich, and illustrated by Antbase (2015) originates probably from Bangka Island offshore Sumatra. Antweb (2015) records specimens from Borneo (Sabah and Kalimantan). Examined specimens from West Malaysia, Sumatra, and Borneo (Sabah and Sarawak) fully agree with illustrations of a Sabah specimen in Antweb (2015).

\section{Echinopla pallipes Smith, 1857}

Fig. 26

Material examined. 2 workers (syntypes?; NHMW) from unknown locality, G. Mayr Collection (see Notes); 1 worker (SCW) from Borneo, Sarawak, Gunung Mulu National Park, dipterocarp forest, $4^{\circ} 02^{\prime} 30^{\prime} \mathrm{N} ; 1^{\circ} 4^{\circ} 52^{\prime} 15^{\prime \prime} \mathrm{E}$, 23-26.X.2009, leg. D.M. Sorger; 1 worker (MCB) from the same area, Camp 1, 402'29'N; 11449'08' E, 3.VI.2006, leg. D. Mezger (C 001862); 1 worker (UKL) from Sabah, Poring Spring, lower montane mixed dipterocarp forest, > $650 \mathrm{~m}$ as.1., on Aporusa sp., 20.V.1992, fogging, leg. A. Floren; 1 worker (NHMW) from Sabah, Poring Spring, lower montane mixed dipterocarp forest, $>650 \mathrm{~m}$ a.s.1., on Xanthophyllum affinis, 21.V.1992, fogging, leg. A. Floren; 1 worker (UKL) from Borneo, Sabah, Poring Hot Spring, leg. A. Malsch.

Notes. Echinopla pallipes is similar to E. melanarctos, but smaller (TL ca. $6 \mathrm{~mm}$ ), and has pale legs, lower tubercles on head and mesosoma and strongly reduced tubercles on gaster tergite 1 (only anteriorly present). It differs from E. tritschleri and E. cherapunjiensis by the posterior position of the eyes, and from E. circulus sp. n. 
by the sculpture of the gaster tergite 1 (comp. Figs 24 and 26). See also notes for E. circulus sp. n.

Smith (1857) described Echinopla pallipes from Sarawak, Borneo. One type specimen (holotype?) is in the Oxford University Museum and has been illustrated in Antweb (2015). Mayr (1862) published some descriptive notes on two specimens (now in NHMW) that he had received from Frederick Smith. Their locality is unclear, but considering the rareness of collections from Borneo in the $19^{\text {th }}$ century they could be syntypes. These three specimens and the two examined specimens from Poring, Sabah, clearly belong to the same species. One further specimen collected by Miss D.M. Sorger in Sarawak is slightly larger and has longer lateral spines on the petiole, but otherwise agrees fairly well in the sculptural details.

Besides the examined specimens from Sarawak, the specimen from Kalimantan Barat in the Indonesian part of Borneo, illustrated by Antweb (2015) and a worker from the Gunung Mulu National Park in northern Sarawak, illustrated by Antbase (2015) and deposited in the Natural History Museum London, can be safely identified as $E$. pallipes. However, E. pallipes is apparently not restricted to Borneo. General and Alpert (2012) report and illustrate a specimen from Luzon, the Philippines, which agrees well with the type in structural details. A record from Sulawesi ("Celebes") by Smith (1862) remains unconfirmed.

\section{Echinopla circulus sp. $\mathbf{n}$.}

http://zoobank.org/D944FB8D-F02E-485C-8ACC-90F7E1D9AE30 Figs 21-25

Type material. Holotype (worker, NHMW) from Borneo, Sarawak, Kelabit Highlands, Bareo - Arur Dalam, ca. 1000 m a.s.1., 26.II.1993, leg. M.A. Jäch (14); 4 paratypes (workers, NHMW, ZCW) same locality, leg. H. Zettel (11); 1 paratype (worker, NHMW) from Borneo, Sabah, Crocker Range National Park, Mawer Waterfall area, undergrowth, 17.VI.1996, unknown collector; 2 paratypes (workers, UKL) from Borneo, Sabah, Poring Hot Spring, 7.I.1998, leg. A. Malsch (8257).

Diagnosis (worker). Predominantly black species with yellowish legs (but tarsi black); relatively large, $\mathrm{TL}=6.4$ $7.6 \mathrm{~mm}$. Surface of head and mesosoma with numerous pedestals, each bearing one long standing black seta and a ring of short pale hairs directed horizontally. Gaster tergite 1 with similar pedestals at base, but their height strongly reduced towards posterior margin, so that they appear as low dimples; additionally with strong, circular ridges (Fig. 24). Head wider than long $(\mathrm{CI}=115-124)$. Mesosoma about one fourth longer than pronotal width (MI 124-132), with narrow, sharp and deep incision in front of propodeum. Pronotal width slightly less than head width, if eyes excluded. Propodeum slightly shorter than promesonotum. Petiole node almost smooth, anteriorly with transverse ridge, dorsally with four small teeth between the lateral spines, without teeth laterally below lateral spine. Setae on dorsal surface, legs and scape abundant, long and mostly black.
Description. Measurements of holotype worker: TL 7.6; HW 2.29; HW 2.07; HL 1.89; EL 0.31; SL 1.78; SW 0.20; HaL 0.55; PML 1.30; PMW 1.98; PpL 1.2; PpW 1.63; PH 0.63; PL 0.53; PW 1.11; GL 2,28; GW 2.38. Indices: CI 121; SI 78; MI 126.

Measurements of paratype workers: TL 6.4-7.8; HW 2.04-2.23; $\mathrm{HW}_{2}$ 1.80-2.07; HL 1.67-1.93; EL 0.290.31; SL 1.57-1.83; SW 0.18-0.21; HaL 0.46-0.58; PML 1.09-1.47; PMW 1.63-1.98; PpL 0.96-1.15; PpW 1.41-1.65; PH 0.55-0.62; PL 0.45-0.51; PW 0.90-1.06; GL 1.96-2.41; GW 2.12-2.32. Indices: CI 116-124; SI 77-84; MI 124-132.

Structures: Head wider than long, roundish, with convex sides; frons, vertex and tempora rugose-tuberculate, the high "pedestals" connected by low ridges; antennal scrobes, part of genae, and clypeus longitudinally rugose; ventral surface smooth and shiny. Ventrolateral ridge forming a distinct angle below eye. Compound eye small, but strongly protruding, positioned distinctly behind midlength of head on a small socket. Frons with long median carina; frontal lobes obliquely elevated, completely covering antennal fossae in dorsal aspect; margins anteriorly slightly converging, their maximum distance near posterior end, distinctly greater than half of $\mathrm{HW}_{2}$. Clypeus subapically with transverse carina; median carina indistinct among longitudinal rugae. Mandibles striate, masticatory margin with five teeth. Antennal scape moderately long, weakly s-curved, steadily widened from base to apex; antennomeres 8-10 slightly longer than wide.

Mesosoma very stout, length roughly 1.3 times pronotum width, dorsal outline regularly convex; propodeum distinctly shorter than promesonotum. Dorsal surface rugose-tuberculate as on vertex; sides irregularly rugose; posterior-most part of propodeum smooth and shiny. Pronotum rounded, distinctly narrower than head excluding eyes. Promesonotal and mesometanotal suture sharp, narrow and (laterally) deep, but both inconspicuous between "pedestals"; promesonotal suture evanescent in medial third. "Waist" in front of propodeum hardly developed. Legs moderately long; femora basally stout, strongly narrowed towards apex.

Petiole small, node square, without dorsal crest; surface smooth; lateral teeth moderately long, directed straight towards sides; dorsally between lateral teeth with two pairs of small denticles; anterior face of node separated from dorsal summit by a fine ridge that is medially evanescent; below strongly developed lateral teeth without further dentition. Gaster tergite 1 wider than long, completely covering the following tergites; hind margin convex, without serration; surface anteriorly with pedestals that are basally almost as high as those on mesosoma, but gradually becoming lower towards hind margin where they are only low tubercles; between these structures with coarse rugae that are more or less arranged in circles.

Pilosity: Trunk dorsally with very long, mostly black, but in some areas pale, standing setae that arise from the apices of tubercles. Short, pale pilosity rather inconspicuous (more conspicuous only on dorsum of mesosoma), often arranged in subapical rings of horizontally projecting 

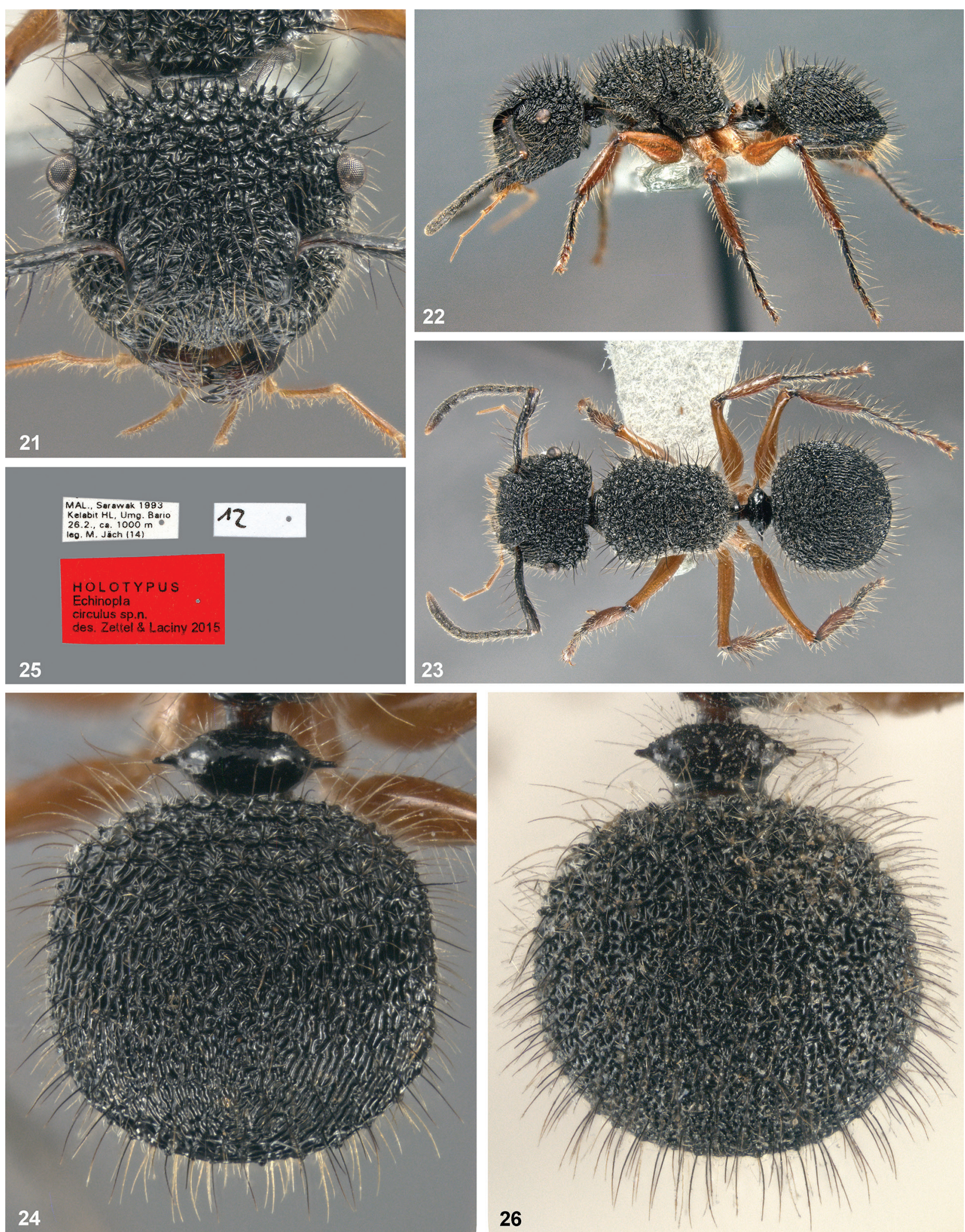

Figures 21-26. (21-25) Echinopla circulus sp. n., holotype: (21) Head, full face view. (22) Habitus, lateral view. (23) Habitus, dorsal view. (24) Dorsal aspect of gaster tergite 1. (25) Labels. (26) Echinopla pallipes, dorsal aspect of gaster tergite 1.

hairs on pedestals. Scape also with very long standing setae. Legs without appressed pilosity, but all parts with numerous, black or white, oblique setae of varying length. Femora with rows of setae on flexor and extensor sides.
Longest setae on middle and hind tibiae as long as those on scape.

Colour: Trunk black, without metallic shimmer; apex of abdomen testaceous. Antenna black or very dark brown, 
extreme base of scape and apex of last antennomere pale. Mandible basally black, distally brown; other mouthparts yellowish to testaceous. Legs chiefly testaceous; forecoxa black (but anteriorly testaceous in the specimen from the Crocker Range); tarsi partly infuscated.

Notes. Echinopla circulus sp. n. is very similar to E. pallipes, but clearly differs in the structure of gaster tergite 1 (compare Figs 24 and 26). A less conspicuous difference is found in the frontal lobes that are parallel in E. pallipes, but anteriorly slightly converging in E. circulus sp. n. (Fig. 21). On average E. circulus sp. n. is larger than E. pallipes (HW 2.04-2.29 in E. circulus sp. n., 1.85-2.02 in E. pallipes including the aberrantly large worker from Gunung Mulu).

Etymology. From the Latin circulus for a small circle and referring to the concentric rugae on gaster tergite 1; used as a noun in apposition.

\section{Echinopla tritschleri Forel, 1901}

Material examined. 9 workers and 1 dealate gyne (ZCW, NHMW) from West Malaysia, Kelantan, 30 km NW Gua Musang, Ulu Lalat, Kampong Sungai Om, 800-1000 m a.s.1., 21.VI.-14.VII.2010, leg. Petr Čechovský; 2 dealate gynes (NHMW) from Borneo, Sabah, Crocker Range National Park, Gunung Emas Highland Resort, 15001700 m a.s.1., 6-18.VI.1998, unknown collector (2a); 3 workers (CAS, CASENT0202195-97) from Borneo, Sabah, Danum Valley, nature trail, $180 \mathrm{~m}$ a.s.1., $4.96072^{\circ} \mathrm{N}$; $117.80014^{\circ} \mathrm{E}, 25$.VIII.2010, rainforest, leg. B.L. Fisher; 1 worker (CAS) from the same locality, 16-26.VIII.2010, Ant Course 2010, unknown collector.

Notes. Echinopla tritschleri differs from the previous three species by the position of the eyes that are close to the mid-length of the head. The short hair of the mesosoma is less conspicuous than in E. pallipes and E. circulus sp. n. The sculpture of gaster tergite 1 is very characteristic: anteriorly with a few tubercles, sides and disc with punctures that flow together to form longitudinal lines, and posteriorly with punctures that flow together into transverse lines.

Gynes similar to workers but differing by the following characters: body much larger (TL 8.4-8.7 vs. 6.1-6.8; HW $2.12-2.19$ vs. $1.58-1.86$ ); eyes slightly larger; ocelli present; scape wider; pedestals comparatively low and restricted to posterior of head, pronotum, propodeum, and base of gaster tergite 1; scutum and scutellum with coarse, irregular rugae, scutum anteriorly with short median carina; short pilosity of dorsum less obvious; thoracic structures as typical for winged ant gynes (all examined specimens with wings broken off); scutellum laterally with a short lobe.

Forel (1901) described the worker of E. tritschleri from Sumatra and added a gyne from southeastern Borneo. From Sabah, northern Borneo, we have studied the worker specimens listed by Antweb (2015) and deposited in CAS, and two gynes in NHMW. The specimens from West Malaysia represent the first record from the Asian mainland.

\section{Echinopla cherapunjiensis Bharti \& Gul, 2012}

Material examined. 2 workers (NHMW) from Laos, Luang Nam Tha Province, ca. 25 km SE Muang Sing, $900 \mathrm{~m}$ a.s.1., 14-15., 20-22.VI.1996, leg. H. Schillhammer (27, 34); 1 worker (ZCW) from West Malaysia, Perak. 40 km SE of Ipoh, Banjaran Titi Wangsa, Ringlet, $900 \mathrm{~m}$ a.s.1., 29.III.-15.IV.2004, leg. Petr Čechovský.

Notes. This species can be characterized by tuberculate sculpture of head and mesosoma, whereas the gaster tergite 1 is polyporous, by black trunk with yellowish legs, scape, and mouthparts, and by white pilosity. It shares the position of eyes with E. tritschleri but can be easily distinguished from this species by relatively low pedestals on head and mesosoma, the polyporous sculpture of tergite 1 , the almost vertically positioned frontal lobes, and a longer and lower, polyporous petiolar node. Bharti and Gul (2012) stated that the mesometanotal suture is obsolete in the holotype of E. cherapunjiensis. However, a re-examination of the type by Professor Himender Bharti revealed the presence of a narrow suture covered by the dense hair (Bharti, in litteris), as in our specimens from Laos and Malaysia, and as in E. tritschleri.

Bharti and Gul (2012) described E. cherapunjiensis based on a single worker from Meghalaya, northeastern India. Liu et al. (2015) published a new record from Yunnan, China. Antweb (2015) illustrated the holotype and an "Echinopla cn01" specimen from Guanxi, China, that apparently belongs to this species. Our first records from Laos and West Malaysia are a considerable extension of the known distribution of E. cherapunjiensis.

\section{Echinopla mezgeri sp. $\mathbf{n}$.}

http://zoobank.org/E621C191-5568-4274-9AB8-8D556D73D444 Figs 27-30

Type material. Holotype (worker, NHMW) from Sabah, Danum Valley, Western Trail, T\#33, 045ㅇ'N; $117^{\circ} 48^{\prime} \mathrm{E}$, 21.VII.2004, leg. D. Mezger (C 003604).

Diagnosis (worker). Predominantly black species with partly yellowish legs; slender and rather small, TL $=5.3$ $\mathrm{mm}$. Trunk with extremely fine sculpture, only meso- and metapleura with coarse punctures. Head much longer than wide $(\mathrm{CI}=86)$. Palp formula 5, 3. Mesosoma about twice as long as pronotal width (MI 205), with sharp, but shallow incision in front of propodeum. Pronotal width smaller than head width, if eyes excluded, with tooth-like lateral corners. Propodeum clearly shorter than promesonotum. Petiolar node stocky, without teeth, with obtuse lateral corners. Gaster tergite 1 much longer than wide, with very dense, extremely fine and shallow puncturation. Body almost without standing setae (some on clypeus and abdominal segments 5 and 6), but with dense, very short, appressed pubescence that gives the species a dull appearance.

Description. Measurements of holotype worker: TL 5.3; $\mathrm{HW}_{1}$ 1.09; $\mathrm{HW}_{2}$ 0.98; HL 1.28; EL 0.36; SL 1.11; SW 0.16; HaL not applicable; PML 0.98; PMW 0.89; 

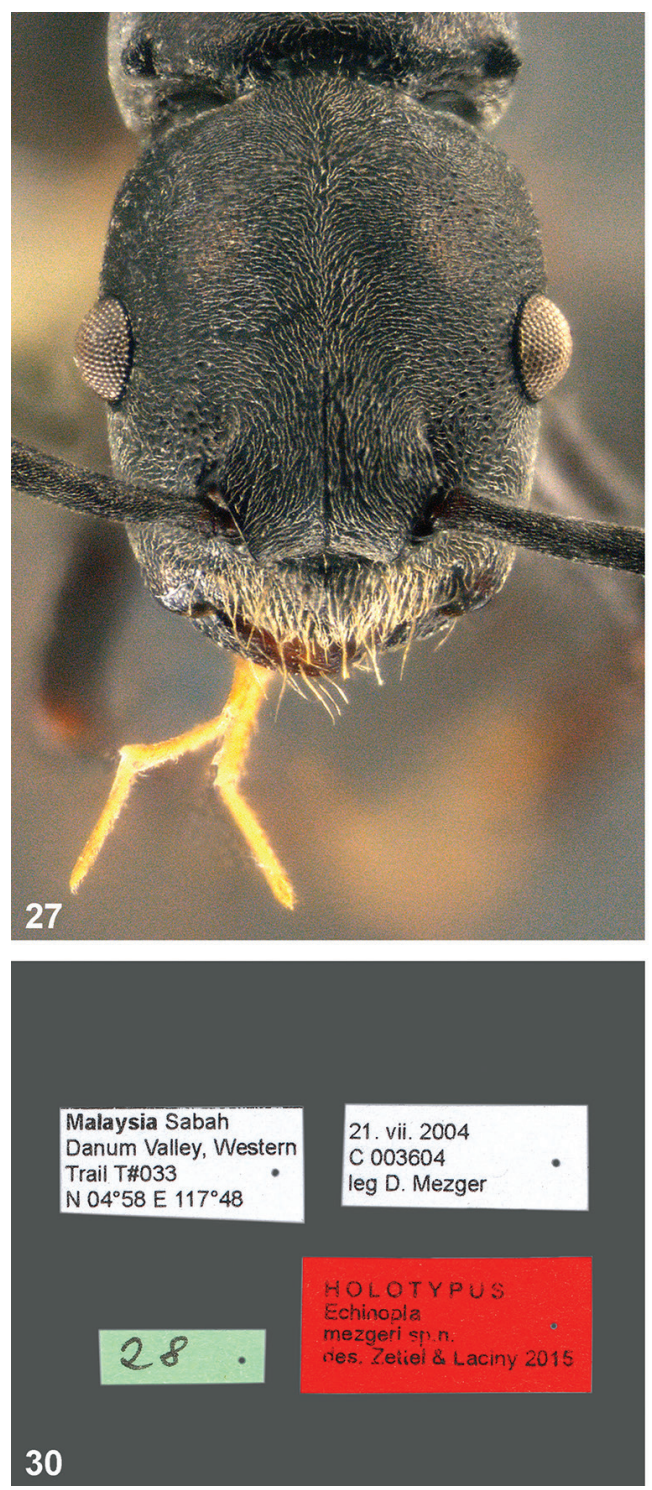

Figures 27-30. Echinopla mezgeri sp. n., holotype:
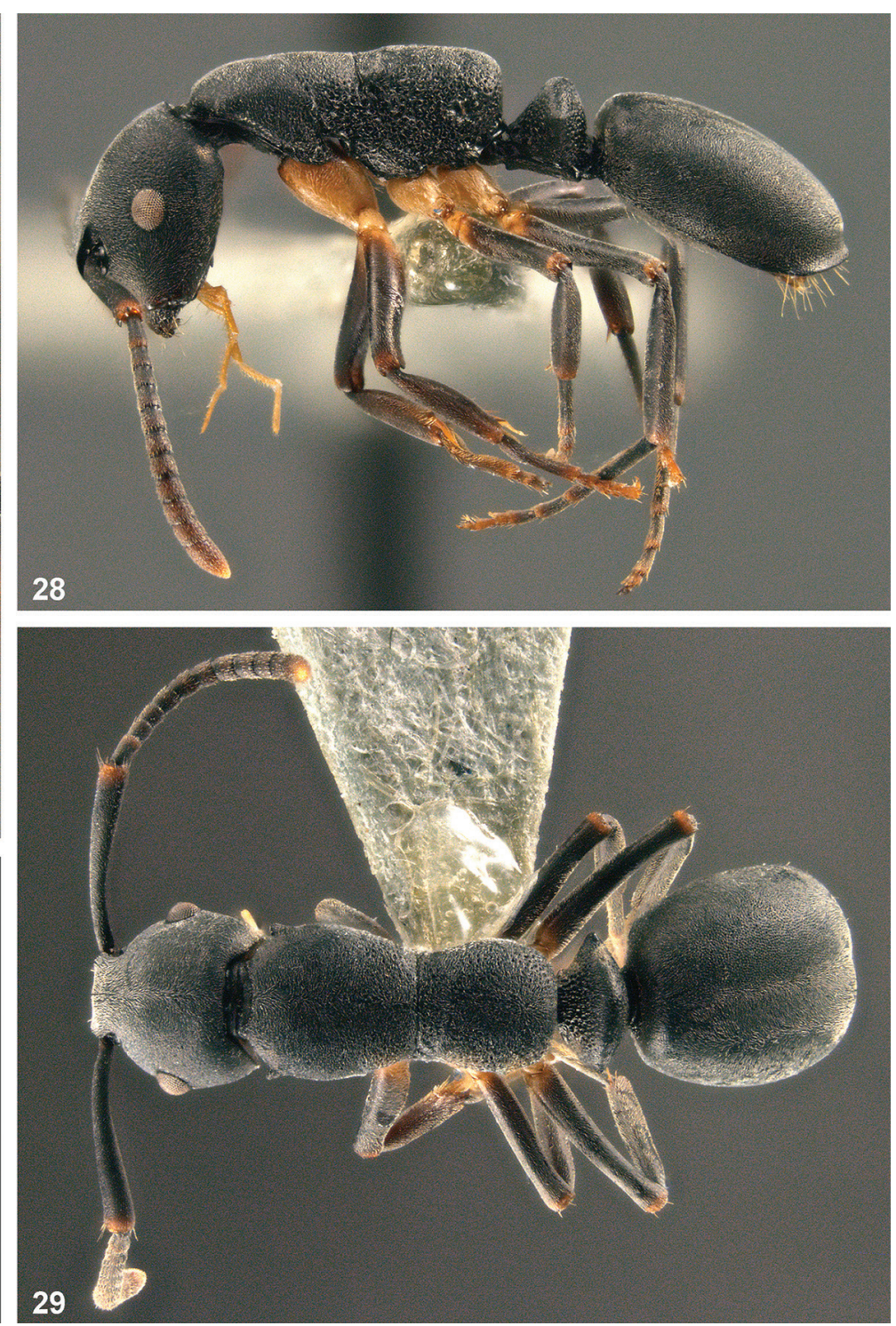
(30) Labels.

PpL 0.85; PpW 0.76; PH 0.55; PL 0.51; PW 0.79; GL 1.50; GW 1.22. Indices: CI 86; SI 102; MI 205.

Structures: Head much long than wide, roundish, with convex sides, with inconspicuous lobe at middle of posterior margin; dorsally and laterally with fine punctures that are evanescent close to the midline, and larger only between antennal fossae and eyes; ventral surface smooth and shiny. Compound eye small, weakly protruding, positioned at mid-length of head. Frons with fine median carina; frontal lobes horizontal, partly covering antennal fossae in dorsal aspect, maximum distance near posterior end equalling half of $\mathrm{HW}_{2}$. Clypeus with median tumescence. Mandibles striate, masticatory margin with five teeth. Palp formula 5, 3. Antennal scape long, weakly s-curved, steadily widened from base to apex; antennomeres 8-10 approximately as long as wide.

Mesosoma very elongated and subcylindrical, length roughly twice pronotum width; dorsal outline shaped as two weakly convex curves separated by a weakly im- pressed mesometanotal suture. Propodeum abruptly declivitous and distinctly shorter than promesonotum. Dorsal surface smooth on major part of pronotum, relatively finely punctured on posterior parts; meso- and metapleura with coarse punctures. Pronotum with tooth-like angles, narrower than head excluding eyes. Promesonotal suture laterally indicated by a short row of punctures; mesometanotal suture narrow and shallow; metanotum recognizable as a narrow ovate depression. "Waist" in front of propodeum weakly developed. Legs long; femora slender.

Petiole relatively large and stout, with a distinct peduncle; node subtriangular in lateral view, spindle-shaped in dorsal view; surface punctured; lateral teeth obtuse, no further dentition. Gaster tergite 1 much longer than wide, completely covering the following tergites in dorsal aspect, very finely and densely punctured; hind margin convex, slightly depressed, without serration.

Pilosity: Body with dense, very short, appressed pubescence giving the species a dull appearance; long standing 
setae restricted to clypeus and abdominal segments 6 and 7; a few short oblique setae on other abdominal sternites.

Colour: Trunk dull black, without metallic shimmer; apex of abdomen testaceous. Antenna blackish brown, apex of scape and distal flagellomeres orange brown. Mandible basally black, distally reddish brown; palpi pale yellow. Legs black, but coxae and trochanters yellow, tarsi pale brownish towards apex.

Comparative notes. Echinopla mezgeri sp. n. is a very peculiar species that resembles E. mistura (Smith, 1860). Echinopla mistura was described by a worker from Bacan Island ("Bachian"), Moluccas, in a new genus Mesoxena in the subfamily Ponerinae (Smith 1860), and indeed the strange cylindrical mesosoma and petiole of the specimen have superficial similarities to some ponerines. Donisthorpe (1936) gave a redescription of the type and confirmed its placement in Formicinae, and Brown (1973) synonymized Mesoxena with Echinopla. The damaged type is illustrated by Antweb (2015). Both E. mistura and E. mezgeri $\mathrm{sp}$. $\mathrm{n}$. have an elongated mesosoma and very fine body sculpture, and - in contrast to all congeners - they lack standing setae. However, there are important differences between the two species and it is presently not certain whether they are closely related. The antennal fossae are fully exposed in E. mistura, whereas they are largely covered by the horizontal frontal carinae in E. mezgeri sp. $\mathrm{n}$. The petiole of E. mistura is square in lateral and dorsal aspect, whereas in E. mezgeri sp. n. it is subtriangular in lateral aspect and spindle-shaped in dorsal aspect. In $E$. mistura the posteriorly flat gaster tergite 1 does not fully cover the following tergites, whereas in E. mezgeri sp. n. it has a downcurved posterior margin and the following segments protrude ventrally. In addition, there are many differences in sculpture, colour of antenna, armature of the pronotum, presence of a metanotal suture, etc. Echinopla mezgeri sp. $\mathrm{n}$. has a palp formula of 5, 3 in contrast to any other species treated here that all have 6,4 , and to $E$. mistura that has according to Smith (1860) six-segmented maxillary palpi (now lacking in the type).

Etymology. We dedicate this extraordinary species to Dirk Mezger (Balingen, Germany) who discovered it.

\section{Echinopla subtilis sp. n.}

http://zoobank.org/4F3F5D00-69A2-433B-A11F-075DBBF02485 Figs $31-34$

Type material. Holotype (worker, NHMW) from Sabah, Poring Spring, lower montane mixed dipterocarp forest, $>650$ m a.s.1., on Aporusa sp., 13.IV.1992, fogging, leg. A. Floren (A62/F1); paratype (worker, NHMW), same locality and collection data, except 9.II.1993, leg. A. Floren (A51/F5).

Diagnosis (worker). Predominantly black, medium -sized, slender species, $\mathrm{TL}=6.1-6.8$. Dorsal surface of head and mesonotum with irregularly winding deep impressions, laterally with smaller fractions, tending to become polyporous. Head wider than long
$(\mathrm{CI}=106-115)$. Maxillary palpi exceptionally long. Mesosoma about one half longer than wide (MI = 151-156). Pronotum much narrower than head, laterally rounded. Propodeum much shorter than promesonotum; promesonotal suture distinct, medially forming an angle; metanotal suture straight, sharp and deep. Petiole polyporous, longer than high, with irregularly tuberculated dorsal crest and 1-2 teeth below prominent lateral spines. Gaster tergite 1 and visible hind margins of the following tergites $2-4$ with very fine, dense puncturation, appearing matt. Setae on dorsal surface white, relatively short.

Description. Measurements of holotype worker: TL 6.1; HW 1.52; HW 1.41; HL 1.33; EL 0.36; SL 1.45; SW 0.17; HaL 0.17; PML 1.04; PMW 1.20; PpL 0.76; PpW 0.91; PH 0.49; PL 0.55; PW 1.00; GL 1.72; GW 1.61. Indices: CI 115; SI 95; MI 151.

Measurements of paratype worker: TL $6.8 ; \mathrm{HW}_{1} 1.65$; HW 1.57; HL 1.57; EL 0.38; SL 1.52; SW 0.18; HaL 0.17; PML 1.13; PMW 1.28; PpL 0.87; PpW 1.00; PH 0.50; PL 0.62; PW 1.08; GL 1.72; GW 1.63. Indices: CI 106; SI 92; MI 156.

Structures: Head slightly wider than long, with convex sides and almost straight hind margin; dorsally with irregularly winding deep impressions, laterally and on clypeus with smaller fractions, tending to become polyporous; ventral surface smooth and shiny. Compound eye slightly protruding, positioned behind midlength of head. Frons with low median carina subdivided by a narrow impression; frontal lobes chiefly horizontally oriented, in fullface view covering most of antennal fossae, maximum distance of margins clearly smaller than half of $\mathrm{HW}_{2}$. Clypeus with low median carina, anterior almost straight (weakly convex). Mandibles striate, masticatory margin with five teeth. Palpi very long. Antennal scape relatively long, weakly s-curved, steadily widened from base to apex; all antennomeres longer than wide.

Mesosoma moderately slender, length slightly more than 1.5 times pronotum width; propodeum much shorter than promesonotum. Dorsal outline of promesonotum and propodeum almost forming a straight line (anteriorly and posteriorly slightly downcurved), interrupted by the incision of a sharp, narrow metanotal groove. Promesonotal suture complete medially forming a blunt angle. Surface as on head, but less conspicuous due to dense pilosity. Few small tubercles along dorsal margins, almost absent from mesonotum. Pronotum anterolaterally rounded, much narrower than head. "Waist" in front of propodeum well developed in dorsal aspect. Legs comparatively long and slender.

Petiole, longer than high, slender subtriangular in lateral, slightly transverse in dorsal aspect; surface sculpture polyporous; dorsal apex bluntly crested, with irregularly set tubercles; below moderately long, apically blunt lateral teeth with one or two smaller teeth. Gaster tergite 1 and visible hind margins of the following tergites $2-4$ with very fine, dense puncturation, appearing mat. Gaster tergite 1 slightly longer than wide, with evenly convex, 

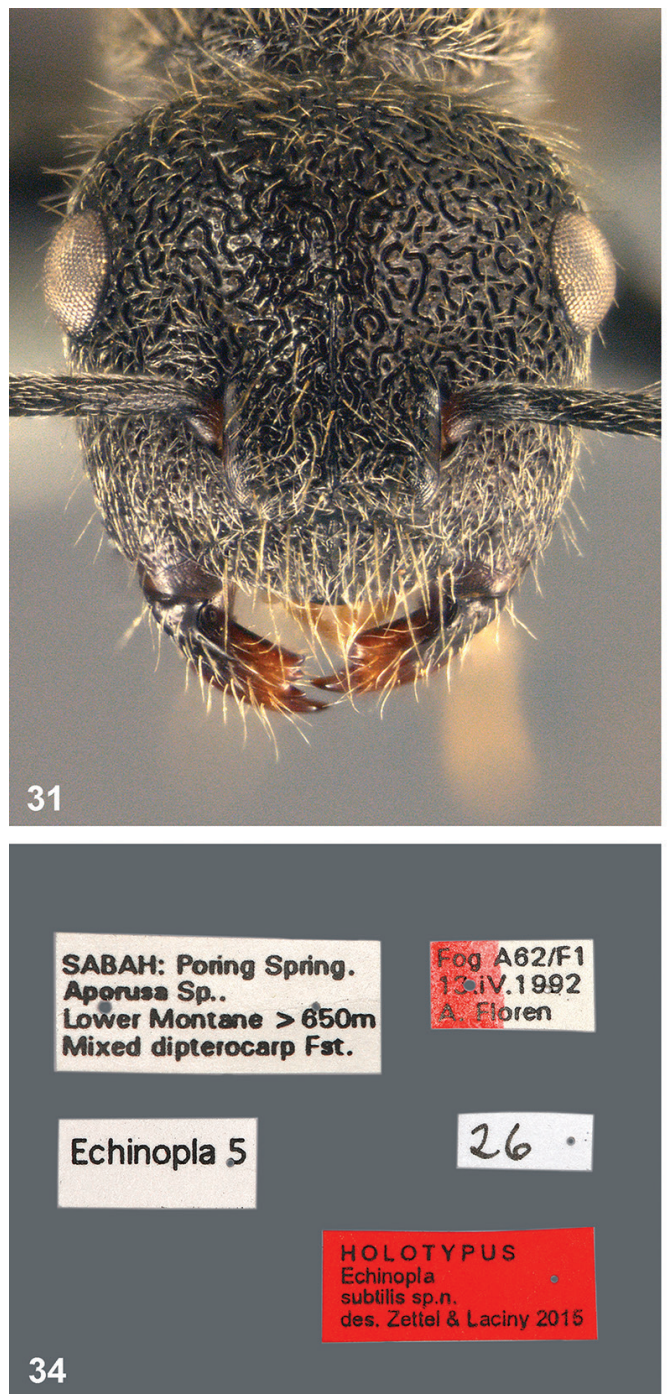
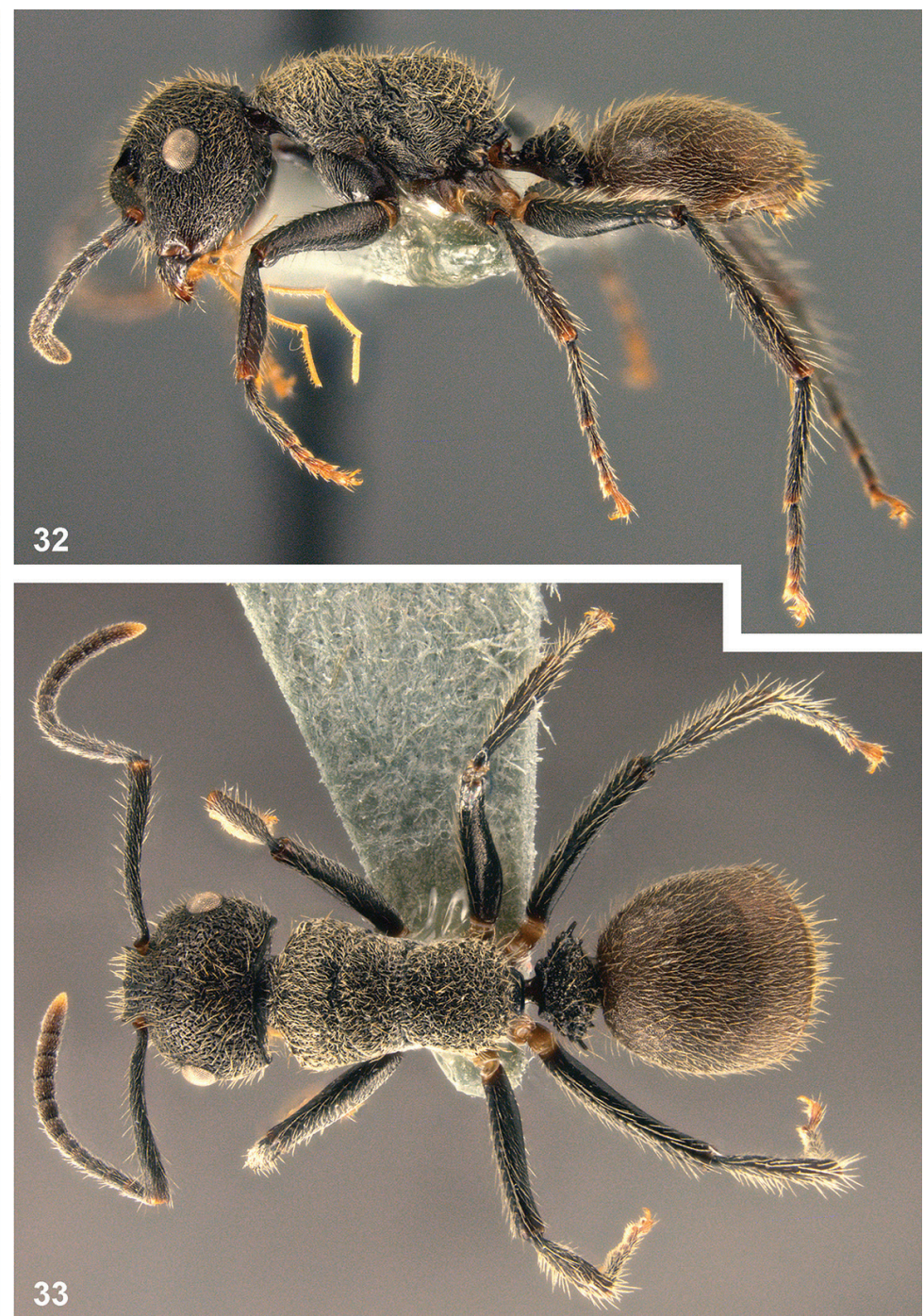

Figures 31-34. Echinopla subtilis sp. n., holotype: (31) Head, full face view. (32) Habitus, lateral view. (33) Habitus, dorsal view. (34) Labels.

unmodified hind margin; insertions of setae appearing as small punctures.

Pilosity: Trunk dorsally and laterally with very dense, appressed white pilosity, but almost absent from centre of face. Dorsal surface with relatively short whitish standing setae, slightly longer on clypeus, propodeum and anterior part of gaster tergite 1. White standing setae on scape, femora, tibiae, and first tarsomeres relatively long.

Colour: Black, without metallic shimmer, mesosoma appearing grey by whitish pilosity. Gaster of holotype dark brown. Gaster tergites 2-4 with narrow whitish hind margin. Mandible basally black, distally reddish. Other mouthparts pale yellow. Apex of last antennomere, apices of middle and hind coxa, trochanters, and distal parts of tarsi orange coloured.

Comparative notes. Echinopla subtilis sp. n. strongly differs from all hitherto described congeners by its sculpture. The dorsal surface of the head and mesosoma has irregularly winding deep impressions; they are best seen in the centre of the face where the pilosity is reduced (Fig. 31). The gaster tergite 1 appears dull due to a very fine and dense puncturation and a relatively dense, appressed pilosity. In contrast to all aforementioned species it does not fully cover the following tergites; this character is shared with the following species that are related to E. lineata and E. striata.

Etymology. The Latin adjective subtilis (= fine, subtle) refers to the fine sculpture of gaster tergite 1.

\section{Echinopla lineata Mayr, 1862}

Figs 35-38, 43

Type material examined. Lectotype (worker, present designation, NHMW) from "Batavia (Novara)" (Mayr 1862); labels see Figure 26. Paralectotypes (2 workers, NHMW), from the same locality.

Additional material examined. 1 worker (NHMW) of unknown origin, leg. Ida Pfeiffer, det. G. Mayr; 1 worker (NHMW) from Java, leg. Vollenhoven, det. G. Mayr; 5 workers (ZCW) from Singapore, Singapore Zoo, 2.XI.2003, leg. H. Zettel; 8 workers (SCV, ZCW) 

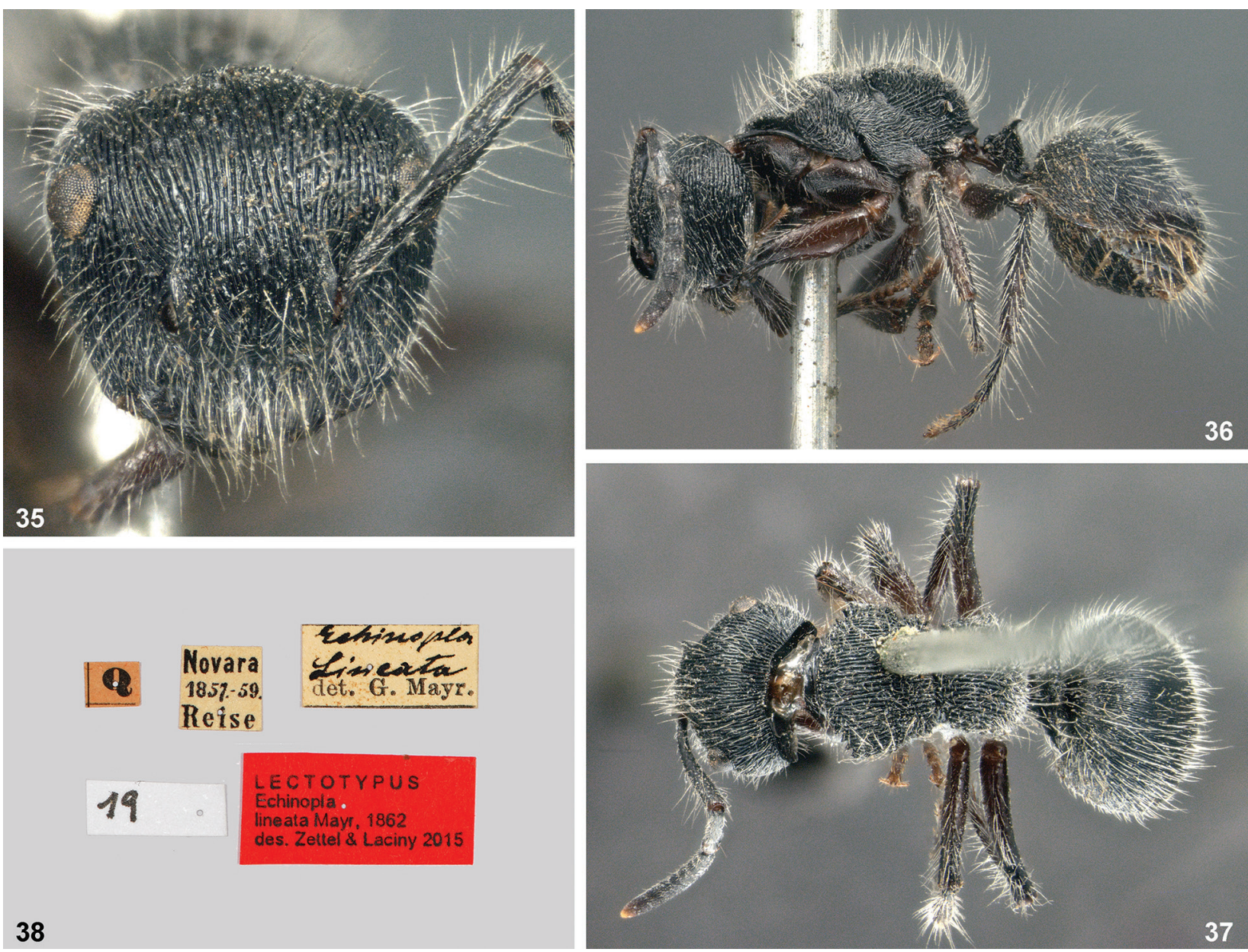

Figures 35-38. Echinopla lineata, lectotype: (35) Head, full face view. (36) Habitus, lateral view. (37) Habitus, dorsal view. (38) Labels.

from Borneo, Sarawak, Mulu National Park, Kerangas Forest behind Mulu Airport, 21.VII.2010, leg. D.M. Sorger; 1 worker (WCD) from Borneo, Sabah, Danum Valley Field Centre, $4.96462^{\circ} \mathrm{N} ; 117.804000^{\circ} \mathrm{E} \pm 70$ m, 180 m a.s.1., 24.VIII.2010, leg. P.S. Ward (\#16476); 5 workers (CAS), from same locality, $525 \mathrm{~m}$ a.s.l., $4.965611^{\circ} \mathrm{N} ; 117.799806^{\circ} \mathrm{E}, 16-26 . V I I I .2010$, rainforest, Ant Course 2010, various collectors; 1 workers (CAS), from same area, Danum Valley, West Trail, $225 \mathrm{~m}$ a.s.1., $4.963056^{\circ} \mathrm{N} ; 117.802806^{\circ} \mathrm{E}, 16-26 . V I I I .2010$, rainforest, Ant Course 2010, unknown collector.

Measurements of the lectotype. TL $6.3 ; \mathrm{HW}_{1}$ 1.66; $\mathrm{HW}_{2}$ 1.58; HL 1.57; EL 0.36; SL 1.39; SW 0.18; HaL 0.48; PML 1.17; PMW 1.50; PpL 1.04; PpW 1.20; PH 0.47; PL 0.51; PW 1.23; GL 1.65; GW 1.80. Indices: CI 106; SI 84; MI 148.

Notes. Echinopla lineata has some similarities with E. striata, especially in sculpture, but can be recognized by the combination of black colour (without metallic lustre), coarse longitudinal striation on head and mesosoma, fine longitudinal striation on gaster, long white setae, and relatively abundant short appressed hair that gives the specimens a dull appearance. See also notes on the similar E. senilis.
The collection of NHMW contains five historical specimens of E. lineata, one of which was erroneously labelled as E. senilis. Three specimens are considered as types, whereas one gyne from Java (see Mayr 1872) and one worker collected by Ida Pfeiffer from an unknown locality are non-type specimens. The worker (paralectotype) labelled "Batavia" (now Jakarta, Java, Indonesia) is missing its head. One worker (paralectotype) bears the same locality code label Q and the same Novara expedition label as the lectotype (see Fig. 38), but a determination label "Echinopla senilis det. G. Mayr" (in Anton Handlirsch's handwriting!) which is probably a curatorial error (see notes for E. senilis). This slightly damaged specimen clearly belongs to E. lineata. The third type specimen, which is in a very good condition (see Figs 35-37), was selected as the lectotype.

The species was originally described from Java (Mayr 1862). This first description is very short, but Mayr (1865) presents illustrations (Fig. 43) and a much more detailed description. Emery (1900) recorded E. lineata from Sumatra. Echinopla sucki was described by Forel (1901) from Sarawak, Borneo, and synonymised by Emery (1925). After having studied the pictures of a syntype of $E$. sucki in Antweb (2015) and non-type specimens from Sarawak, 

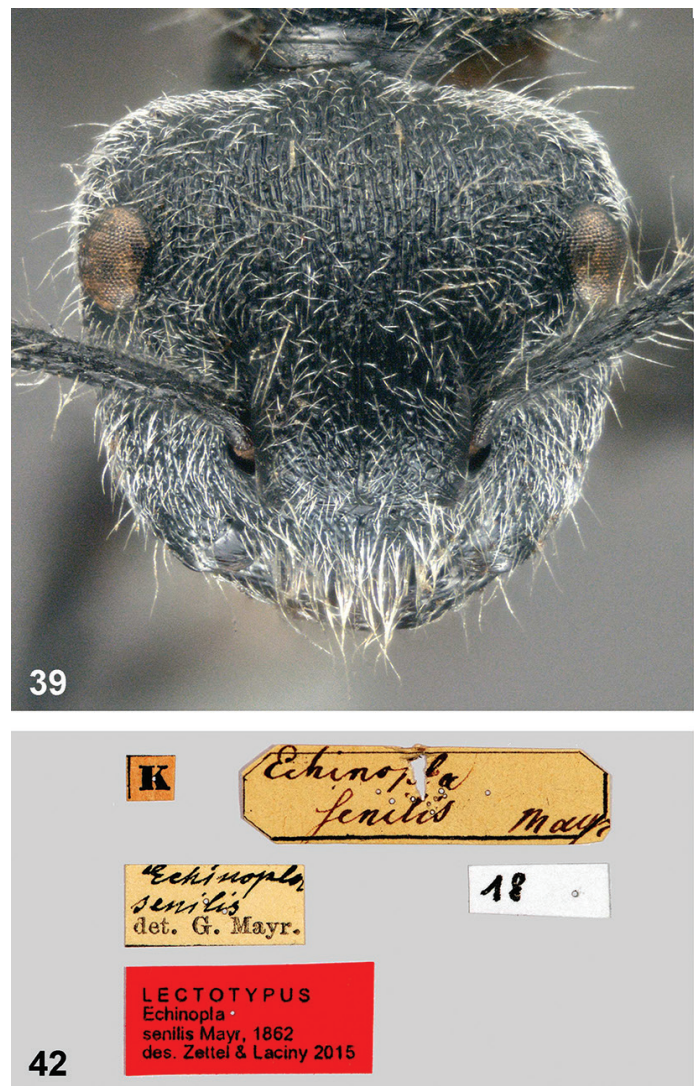
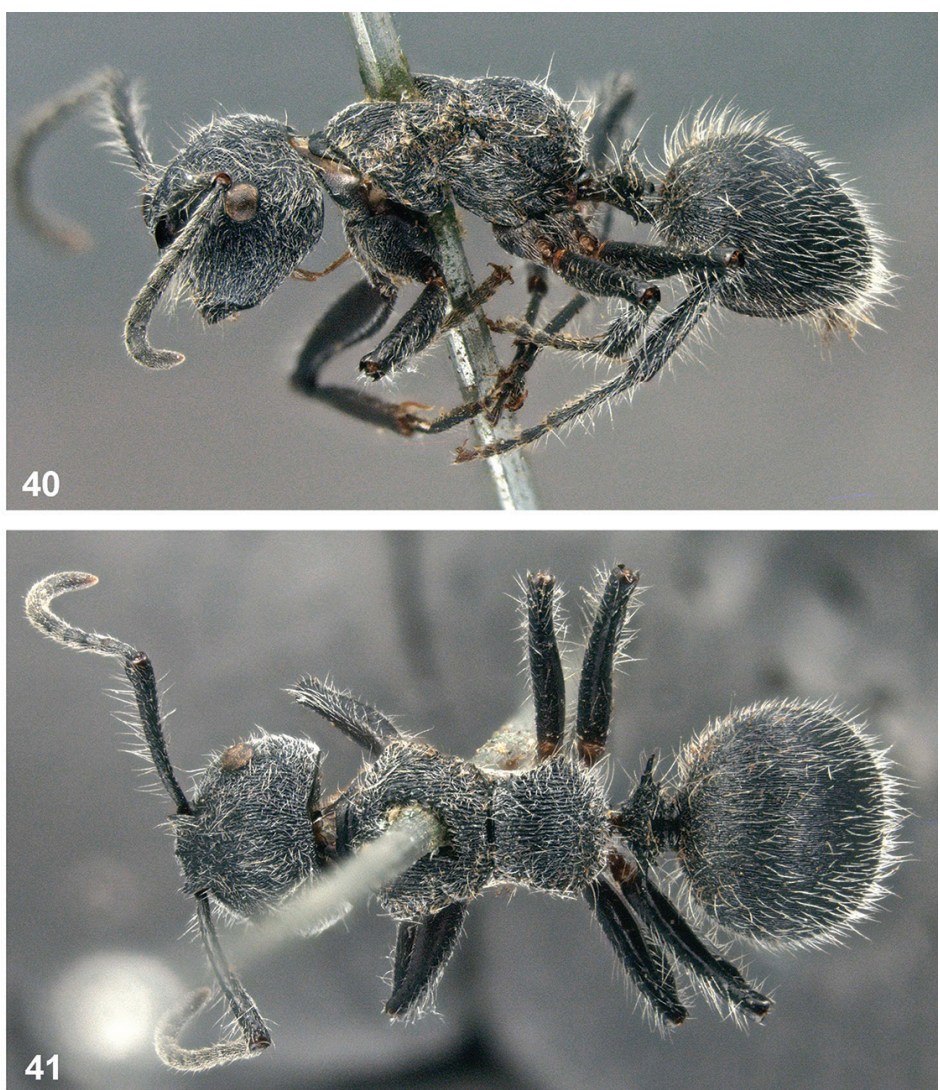

Figures 39-42. Echinopla senilis, lectotype: (39) Head, full face view. (40) Habitus, lateral view. (41) Habitus, dorsal view. (42) Labels.

we affirm this synonymy. We also confirm the presence of E. lineata in Sabah, northern Borneo, based on examined worker specimens in the P.S. Ward Collection and in the California Academy of Sciences. Antweb (2015) records two specimens from Sabah (not examined), but the illustrated one from the Maliau Basin is not E. lineata, because it differs strongly by a fine sculpture of head and thoracic nota, by long black pilosity and the almost absent short hair on the thoracic nota; except for its non-metallic colour it resembles E. striata. Also the Antweb (2015) record of E. lineata in Singapore can be confirmed after having studied the illustrations of this specimen and additionally collected specimens. Antbase (2015) illustrates a correctly identified worker from Kuala Lumpur, West Malaysia, in the Natural History Museum in London.

\section{Echinopla senilis Mayr, 1862, stat. rev.}

Figs 39-43

Type material examined. Lectotype (worker, present designation) from "Sambelong" (Mayr 1862); labels see Figure 42.

Measurements of the lectotype. TL 7.2; $\mathrm{HW}_{1}$ 1.85; HW 1.80; HL 1.67; EL 0.37; SL 1.72; SW 0.20; HaL 0.36; PML 1.30; PMW 1.63; PpL 1.13; PpW 1.28; PH 0.50; PL 0.55; PW 1.28; GL 1.96; GW 2.15. Indices: CI 110; SI 93; MI 149.
Notes. Although the collection of NHMW contains two specimens labelled as E. senilis, only one specimen fairly agrees with Mayr's (1862) original description and is designated as the lectotype. This lectotype does not bear a locality label and we do not know about records that connect the code letter K (Fig. 42) with a specific locality of the Novara expedition. We trust Mayr (1862) that the type was collected in "Sambelong", a name for the Southern Group of the Nicobar Islands. The second specimen in NHMW was probably mislabelled by the former curator Anton Handlirsch (1865-1935) when he integrated Mayr's collection into the museum's main collection. It is a typical specimen of E. lineata and bears the same code letter Q as the lectotype of E. lineata (see notes of this species).

Echinopla senilis is very similar to E. lineata. It was treated as a variety of E. lineata by Emery (1896) and as a subspecies by Emery (1900). It is currently catalogued as a subspecies by Bolton (2015). With more specimens of $E$. lineata available, some differences given by Mayr (1862) and subsequently by Mayr (1865) are not diagnostic. In fresh specimens of $E$. lineata the appressed hair is as abundant as in E. senilis, and the shape of the petiole (comp. Mayr 1865: tab. II, Figs 12c and 13c; see Fig. 43) is rather variable. A bluish black colour of the body ("blauschwarz" in Mayr 1862, "dunkelblau" in Mayr 1865) can hardly be recognized in the lectotype of E. senilis (Figs 39-41). However, the sculptural differ- 


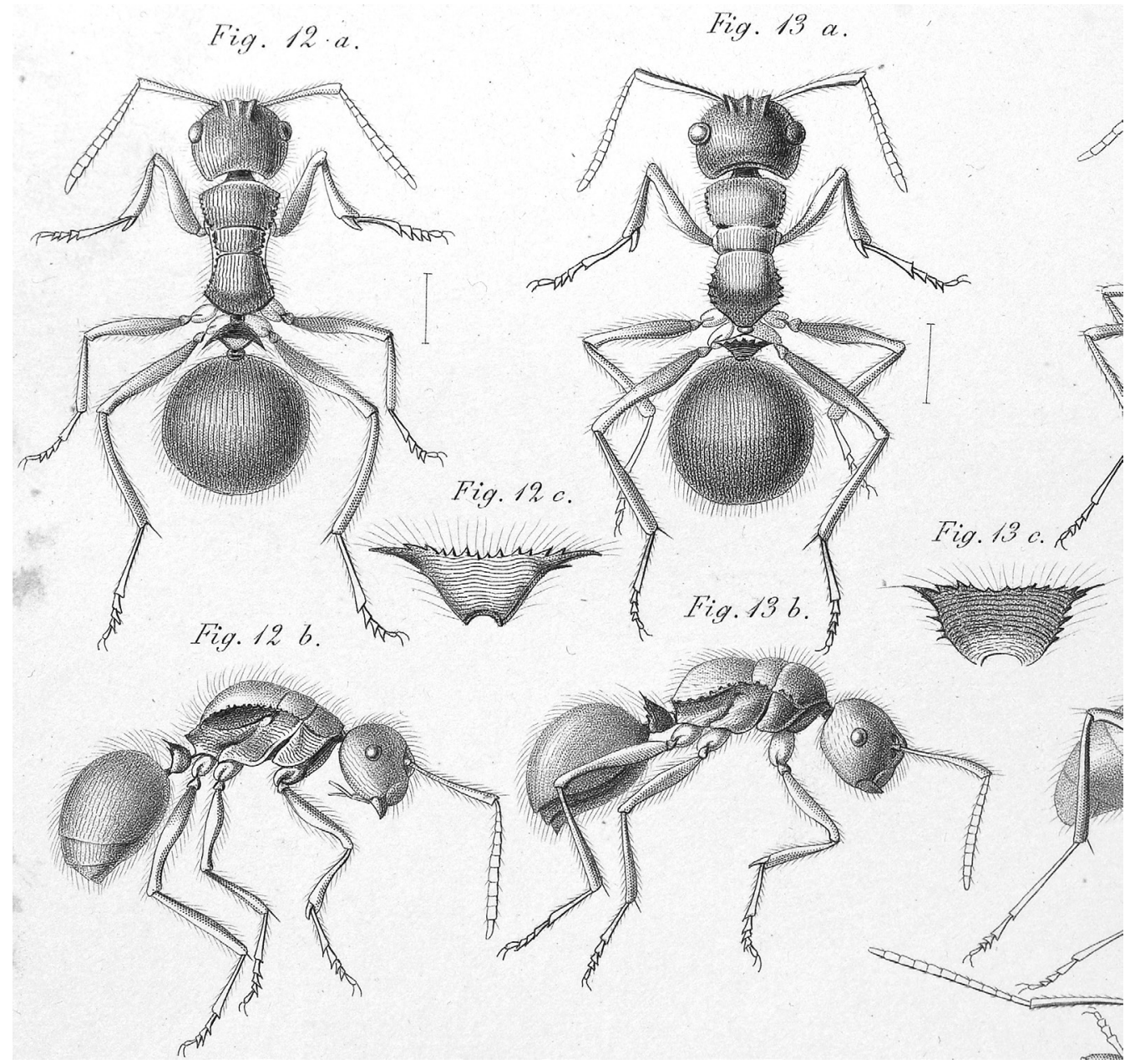

Figure 43. Part of plate II in Mayr (1865) showing Echinopla lineata (fig. 12) and Echinopla senilis (fig. 13).

ences are rather strong and were clearly pointed out by Gustav Mayr (1862, 1865): On the clypeus and on the sides of the mesosoma the striation is regularly striate in E. lineata whereas it is intermixed with punctures in E. senilis; at the hind margin of the propodeum and on the posterior face of the petiole, the sculpture consists of transverse striae in E. lineata whereas it is irregular and fine in E. senilis. Moreover the propodeum is anteriorly more strongly, more roundly constricted in E. senilis. We conclude that $E$. senilis should better be regarded as a distinct species.

\section{Echinopla cf. pseudostriata Donisthorpe, 1943}

Material examined. 5 workers (ZCW) from the Philippines, Cebu Province, Cebu Island, Dalaguete, Mantalungon, 19.II.2012, leg. C. V. Pangantihon (CP406).

Notes. Donisthorpe (1943) described E. pseudostriata based on two syntype workers, one from Sulawesi, Indonesia, and one from Luzon, the Philippines. The studied specimens from Cebu Island differ considerably from the Sulawesi syntype illustrated by Antweb (2015), especially by the more regularly and finely striate sculpture of the mesosoma. Nevertheless we preliminarily identify them as E. cf. pseudostriata, because the species identity and type locality should be fixed by the designation of a lectotype, and the sculptural variability should be examined in more specimens.

\section{Echinopla cf. vermiculata Emery, 1898}

Material examined (all from the Philippines). 1 worker (CAS, CASENT0267357) from Luzon, Mt. Banahaw de Lucban, $747 \mathrm{~m}$ a.s.1., $14^{\circ} 05.859^{\prime} \mathrm{N} ; 121^{\circ} 31.071^{\prime} \mathrm{E}, 14$ 22.V.2011, forest, PH0009, leg. H Wood et al.; 1 worker (NHMW) from Luzon, Nueva Viscaya Province, Santa Fe, Imugan, 1100-1200 m a.s.1., 10.XI.2002, leg. H. Zettel; 1 worker (ZCW) from Luzon, Quezon Province, Atimonan, near Old Zigzag Road, 24-30.III.1998, leg. Zettel (165); 1 worker (ZCW) from Luzon, Laguna Province, Los Baños, Mt. Makiling, 400-800 m, 27.XI.1999, leg. H. Zettel (211); 1 worker (ZCW) from Luzon, Camarines Norte Province, south of Daet, Basud, Nalisan, 13.III.2006, leg. H. Zettel, R. Gille \& L. S. Vichozo (446); 1 worker (ZCW) from Luzon, Pampanga, Arayat, Mt. Arayat, 19-20.IV.2014, leg. C. V. Pangantihon (P506); 
1 worker (ZCW) from Mindoro, Mindoro Oriental Province, Roxas, San Vicente, Taugad Diit, Taugad Daka Forest, 27.IX.2014, leg. C. V. Pangantihon (P513); 2 workers (ZCW) from Cebu Province, Cebu Island, Dalaguete, Mantalungon, 29-30.VIII.2010 and 19.II.2012, leg. C. V. Pangantihon (P361, CP406).

Notes. The identity of this species is presently unclear. Emery (1898) described a queen from Sulawesi and later he (Emery 1900) described workers from two localities on Sipora, an island of the Mentawai group. The type and one worker specimen from Sipora were imaged by Antweb (2015), but their conspecificity needs confirmation. General and Alpert (2012) report E. vermiculata from the Philippines (Luzon) for the first time; one specimen was illustrated on the Discover Life (2015) website. Examined specimens from the islands of Luzon, Mindoro and Cebu perfectly agree with this illustration in structural details. However, all Philippine workers considerably differ from Indonesian specimens by a very coarse, irregularly vermiculate rugosity on mesonotum and propodeum and may in fact represent an undescribed species. The worker specimen in the California Academy of Sciences was listed by Antweb (2015) as Echinopla ph01 and sent for barcoding (Guelph CCDB-14532).

\section{Acknowledgements}

We thank Carsten Brühl (University of Koblenz-Landau), Brian L. Fisher (California Academy of Sciences), Dirk Mezger (Balingen), Clister V. Pangantihon (Ateneo de Manila University), D. Magdalena Sorger (North Carolina State University), and Philip S. Ward (University of California) for making interesting specimens available; C. Brühl, D. Mezger and P.S. Ward also for donating holotypes to NHMW; Professor Himender Bharti (Punjabi University Patiala) for a re-examination of the holotype of E. cherapunjiensis; Dominique Zimmermann (Natural History Museum Vienna) for access to the NHMW collection; Harald Bruckner (Natural History Museum Vienna) for preparing Figure 43; Wolfgang Brunnbauer (Natural History Museum Vienna) for help and access to the NHMW library; P.S. Ward for linguistic corrections and helpful notes on the manuscript. Thanks are also owed to the Museum für Naturkunde, Berlin, for facilitating the open access publication of this paper and to Donat Agosti for his kind review.

\section{References}

André E (1892) Voyage de M. Chaper à Bornéo. Catalogue des fourmis et description des espèces nouvelles. Mémoires de la Société Zoologique de France 5: 46-55.

Antbase (2015) http://www.antbase.net [accessed 25 January 2015]

Antweb (2015) http://www.antweb.org [accessed 25 January 2015]
Bharti H, Gul I (2012) Echinopla cherapunjiensis sp. n. (Hymenoptera, Formicidae) from India. Vestnik zoologii 46 (4): 371-373. doi: $10.3897 /$ zookeys.477.8775

Bolton B (2015) An online catalog of the ants of the world. http://www. antcat.org [accessed 25 January 2015]

Brown WL Jr. (1973) A comparison of the Hylean and Congo-West African rain forest ant faunas. In: Meggers BJ, Ayensu ES, Duckworth WD (Eds) Tropical forest ecosystems in Africa and South America: a comparative review. Smithsonian Institution Press, Washington, D.C., 161-185. doi: 10.5281/zenodo.17403

Discover Life (2015) http://www.discoverlife.org [accessed 25 January 2015]

Donisthorpe H (1936) A new study of Mesoxena mistura Smith. Proceedings of the Royal Entomological Society of London, Series B 5:119-120. doi: 10.1111/j.1365-3113.1936.tb00605.x

Donisthorpe H (1943) Descriptions of new ants, chiefly from Waigeu Island, N. Dutch New Guinea. Annals and Magazine of Natural History (11) 10: 167-176. doi: 10.1080/03745481.1943.9728007

Emery C (1896) Saggio di un catalogo sistematico dei generi Camponotus, Polyrhachis e affini. Memorie della Reale Accademia delle Scienze dell'Istituto di Bologna, series V, 5(1): 761-780.

Emery C (1898) Descrizioni di formiche nuove malesi e australiane. Note sinonimiche. Rendiconti delle Sessioni della Reale Accademia delle Scienze dell'Istituto di Bologna, Nuova Series, 2: 231-245.

Emery C (1900) Formiche raccolte da Elio Modigliani in Sumatra, Engano e Mentawei. Annali del Museo Civico di Storia Naturale 40: 661-722.

Emery C (1925) Hymenoptera. Fam. Formicidae. Subfam. Formicinae. Genera Insectorum 183: 1-302.

Forel A (1901) Formiciden des Naturhistorischen Museums zu Hamburg. Neue Calyptomyrmex-, Dacryon-, Podomyrma- und EchinoplaArten. Mitteilungen aus dem Naturhistorischen Museum in Hamburg 18: 43-82. doi: 10.5281/zenodo. 14254

General D, Alpert GD (2012) A synoptic review of the ant genera (Hymenoptera, Formicidae) of the Philippines. ZooKeys 200: 1-111. doi: 10.3897/zookeys.200.2447

Gnatzy W, Maschwitz U (2006) Pedestal hairs of the ant Echinopla melanarctos (Hymenoptera, Formicidae): morphology and functional aspects. Zoomorphology 125.2: 57-68. doi: 10.1007/s00435005-0011-8

Liu C, Guénard B, Garcia FH, Yamane S, Blanchard B, Yang DR, Economo E (2015) New records of ant species from Yunnan, China. ZooKeys 477: 17-78. doi: 10.3897/zookeys.477.8775

Mayr G (1862) Myrmecologische Studien. Verhandlungen der Kaiserlich-Königlichen Zoologisch-Botanischen Gesellschaft in Wien 12: 649-776.

Mayr G (1865) Formicidae. In: Reise der Österreichischen Fregatte „Novara“ um die Erde in den Jahren 1857, 1858, 1859. Zoologischer Theil. Band II, Abteilung 1. K. Gerold‘s Sohn, Vienna, 119 pp.

Mayr G (1872) Formicidae Borneenses collectae a J. Doria et O. Beccari in territorio Sarawak annis 1865-1867. Annali del Museo Civico di Storia Naturale 2: 133-155.

Smith F (1857) Catalogue of the hymenopterous insects collected at Sarawak, Borneo; Mount Ophir, Malacca; and at Singapore, by A.R. Wallace [part]. Journal and Proceedings of the Linnean Society of London, Zoology 2: 42-88. doi: 10.1111/j.1096-3642.1857. tb01759.x 
Smith F (1860) Catalogue of hymenopterous insects collected by $\mathrm{Mr}$ A. R. Wallace in the islands of Bachian, Kaisaa, Amboyna, Gilolo, and at Dory in New Guinea. Journal and Proceedings of the Linnean Society of London, Zoology 5(17b): 93-143.

Smith F (1862) A list of the genera and species belonging to the family Cryptoceridae, with descriptions of new species; also a list of the species of the genus Echinopla. Transactions of the Entomological Society of London (3) 1: 407-416. doi: 10.1111/j.1365-2311.1862. tb01287.x

Stitz H (1938) Neue Ameisen aus dem indo-malayischen Gebiet. Sitzungsberichte der Gesellschaft Naturforschender Freunde zu Berlin 1938: 99-122. 